\title{
A COMPARISON OF THE MICROMORPHOLOGY OF THE G1 OF FRESHWATER CRABS OF THE GENUS GEOTHELPHUSA (BRACHYURA, POTAMIDAE) FROM TAIWAN
}

\author{
BY \\ WEN-JOU CHEN ${ }^{1,3}$ ), JIN-HUA CHENG ${ }^{2}$ ), TZYY-ING CHEN ${ }^{2}$ ) and MINNA J. HSU ${ }^{1,4}$ ) \\ 1) Department of Biological Sciences, National Sun Yat-sen University, Kaohsiung 804, Taiwan, \\ R.O.C. \\ 2 ) Tungkang Biotechnology Research Center, Fisheries Research Institute, Pingtung 928, Taiwan, \\ R.O.C. \\ $\left.{ }^{3}\right)$ Jyn-Jeng Junior High School, Pingtung 900, Taiwan, R.O.C.
}

\begin{abstract}
Scanning electron microscopy (SEM) was used to compare the micromorphology of the male first gonopods (G1) of 22 species of common Taiwanese potamid crabs of the genus Geothelphusa Stimpson, 1858. Electron micrographs were taken from dorsal, lateral, and apical views of the terminal segment, the sub-terminal segment, and the synovial membrane; and a total of five measurements was taken, i.e., synovial membrane length (SML) and width (SMW), sub-terminal segment width (SW), and terminal segment length (TSL) and width (TSW). In addition, the diameter of the apical opening of the ejaculatory canal (AD), the number of scale rings, the setal type, and the direction of the curve of the tip of the terminal segment were recorded. In adult female crabs, the mean of the diameter of the gonopores and the distance between these were also measured. The scanning electron micrographs of the G1 are all shown in the present paper.
\end{abstract}

\section{RÉSUMÉ}

La microscopie électronique à balayage (SEM) a été utilisée pour comparer la micromorphologie des premiers gonopodes mâles (G1) de 22 espèces communes de crabes Potamidae de Taiwan du genre Geothelphusa Stimpson, 1858. Les microphotographies du segment terminal, du segment subterminal et de la membrane synoviale ont été prises en vues dorsales, latérales et apicales; un total de cinq mesures a été effectué, soient la longueur de la membrane synoviale (SML) et sa largeur (SMW), la largeur du segment sub-terminal (SW), ainsi que la longueur du segment terminal (TSL) et sa largeur (TSW). De plus, le diamètre de l'ouverture apicale du canal éjaculateur (AD), le nombre des anneaux d'écailles, le type de soies et la direction de la courbe de l'extrémité du segment terminal ont été examinés. Chez les crabes adultes femelles, la moyenne du diamètre des gonopores et la distance entre ces derniers ont été également mesurées. Les microphotographies à balayage des G1 sont toutes présentées dans le présent article.

${ }^{4}$ ) Corresponding author; e-mail: hsumin@mail.nsysu.edu.tw 
INTRODUCTION

The freshwater crabs of Taiwan comprise two families and four genera, viz., of the Potamidae Ortmann, 1896: Geothelphusa Stimpson, 1858, Nanhaipotamon Bott, 1968, and Candidiopotamon Bott, 1967; and of the Parathelphusidae Alcock, 1910: Somanniathelphusa Bott, 1968 (cf. Shy et al., 1994, 2000; Chen et al., 1998, 2003, 2005; Tan \& Liu, 1998; Dai, 1999; Shy \& Yu, 1999; Ng et al., 2001; Shy, 2005). All four genera include species from China, Japan, or other countries. However, the freshwater crabs from Taiwan belonging to these four genera are all endemic in Taiwan (Shy et al., 1994; Shy \& Yu, 1999; Ng et al., 2001). There are 35 species in the genus Geothelphusa recorded from Taiwan now. Shih et al. (2004) used the small subsegment of the mitochondrial 16S rRNA encoding gene in partial sequencing (550 bp) to assess the systematics of the southern Taiwanese Geothelphusa species. They suggested some species would be synonyms. In view of the biological species concept, variation in the morphology of the copulatory organs should result in rapid reproductive isolation, and hence in acceleration of the speciation process (Mayr \& Ashlock, 1991; Schluter, 1996). Therefore, we still use the taxonomic system of Shy et al. (1994) and $\mathrm{Ng}$ et al. (2001), which are based on differences in characters of the male first gonopod (G1) to distinguish between species of these freshwater crabs (Ng, 1988; Ng \& Naiyanetr, 1993; Shy et al., 1994; Dai, 1999).

The aims of the this study are (1) to investigate the detailed micromorphology of the G1 with scanning electron microscopy (SEM) in order to supplement the gross morphology now depicted in line drawings in the early days of the systematic studies on this genus; (2) to identify species-defining gonopod characters, and thus use the morphology of the G1 as a key character in the taxonomy of the potamids of the genus Geothelphusa in Taiwan.

\section{MATERIAL AND METHODS}

For the present study, 22 of the more common Taiwanese species of Geothelphusa were selected, and of these topotype specimens were collected from the type locality (Shy et al., 1994). Specimens were examined, preserved in $70 \%$ ethanol, and deposited in the Department of Biological Sciences, National Sun Yat-sen University (NSYSU), Kaohsiung, and the National Taiwan Ocean University (NTOU), Keelung. The methods used in scanning electron microscopy by Felgenhauer (1987) were modified to observe the male G1 with the aid of a HITACHI S-2400 SEM equipped with a digital camera that stores the pictures. The pictures thus obtained were next transferred to a computer for comparison. A total of 1-3 individuals of each species was examined by SEM for the right G1, 

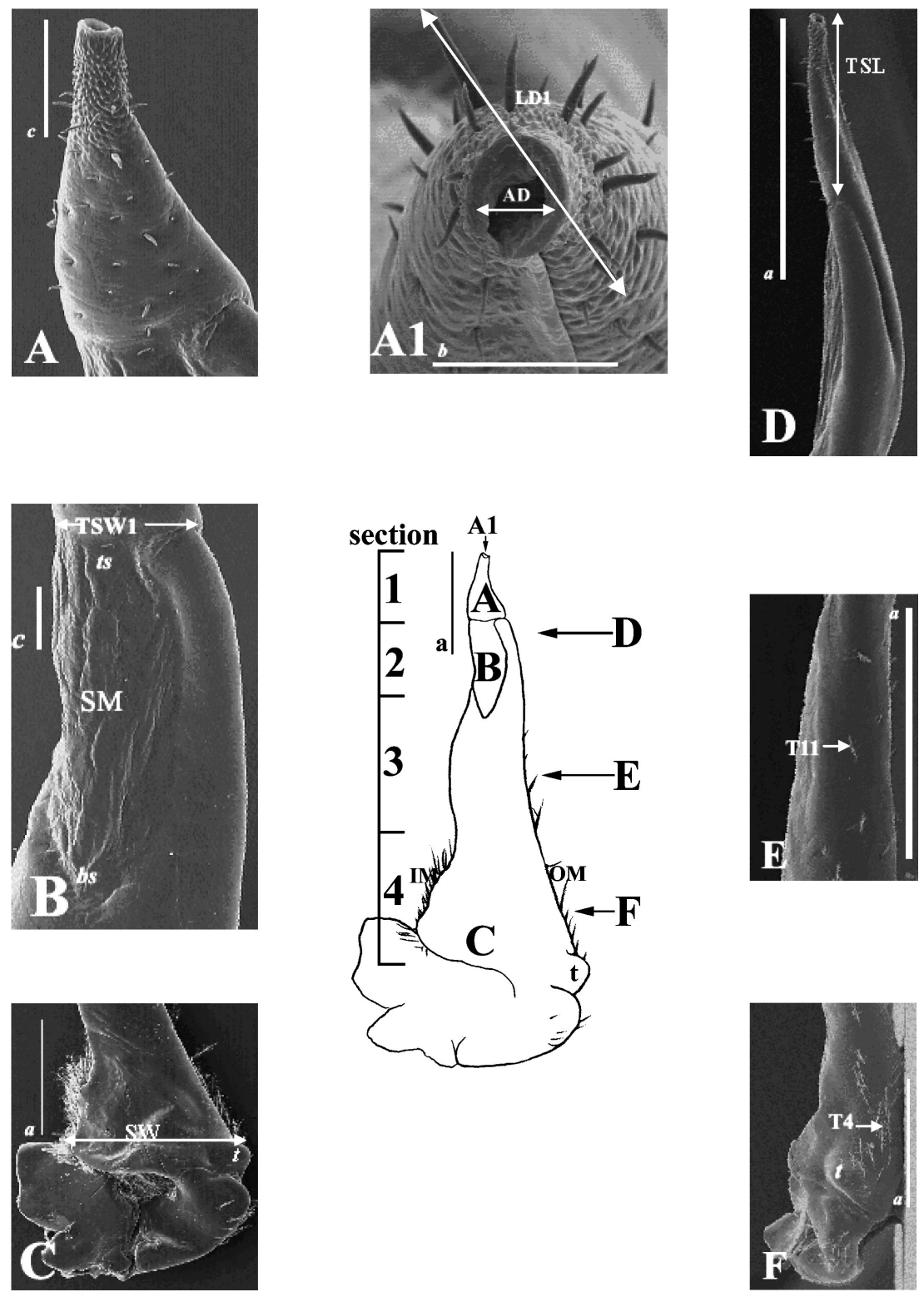

Fig. 1. Micromorphology of the right first gonopod (G1) of Geothelphusa eucrinodonta Shy, Ng \& Yu, 1994, $15.3 \times 11.9$ mm (NSYSU F710041), by SEM; middle panel, external morphology (dorsal view) with line drawings. Section 1 , terminal segment (A); 2-4, sub-terminal segment (B-C); D-F, lateral view; A1, apical tube aperture of G1 (top view); AD, apical aperture diameter of tube; IM, inner margin; OM, outer margin; SM, synovial membrane; SW, sub-terminal segment width; TSW, terminal segment width; TSL, terminal segment length; $b s$, basal margin of synovial membrane; $t s$, top margin of synovial membrane; $t$, outer proximal margin tooth or protuberance of sub-terminal segment. Some parts are magnified in fig. 2. Scales: $a=1 \mathrm{~mm} ; b=100 \mu \mathrm{m} ; c=200 \mu \mathrm{m}$. 


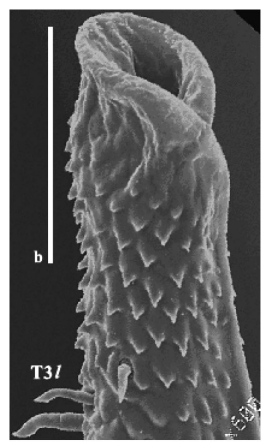

A1

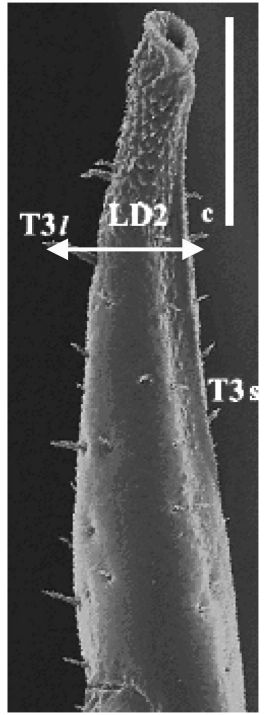

A2

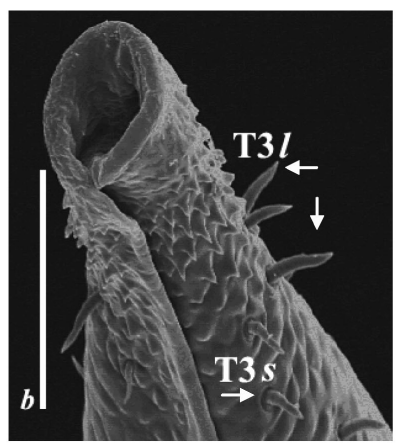

\section{B1}

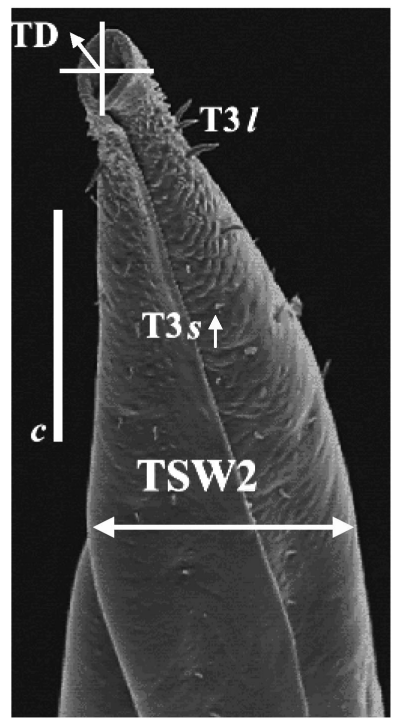

B2

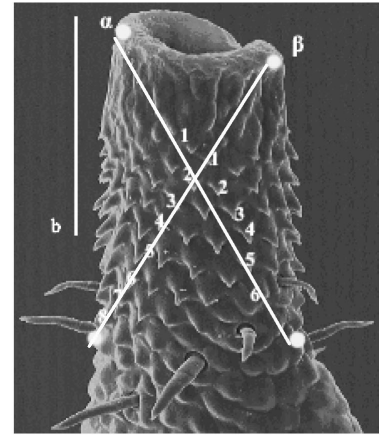

C

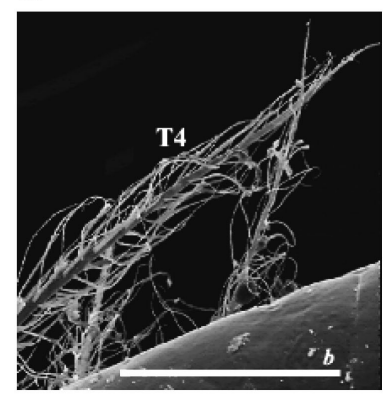

D

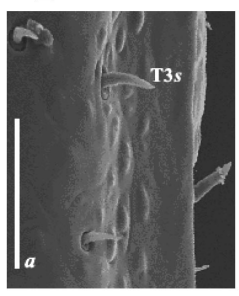

E

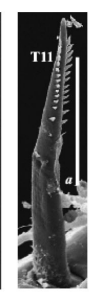

F G

Fig. 2. Micromorphology of the right first gonopod (G1) of Geothelphusa eucrinodonta Shy, Ng \& Yu, 1994, $15.3 \times 11.9$ mm (NSYSU F710041), by SEM. A1-2, lateral view; B1-2, ventral view; C, Arabic numerals represent scale rings counted on intersecting diagonals in two directions $(\alpha, \beta)$; LD, maximum diameter of terminal segments distal part, measured over the longest spines; TD, tip curve direction of G1; TSW, terminal segment width. Setal types: T3, simple; T4, plumose; T11, serrate;

$l$, long simple setae, $s$, short simple setae. Scales: $a=50 \mu \mathrm{m} ; b=100 \mu \mathrm{m} ; c=200 \mu \mathrm{m}$.

and at least another 2-3 individuals were dissected and checked with an Olympus ZSH10 dissecting microscope, also equipped with a digital camera (Moticam 480, Motic Images Plus 2.0). The scanning electron micrographs of the G1 of some species have already been published in Chen et al. (2003). At present, the 22 common species now treated revealed more details, that could represent elements of a common type of morphology of the G1 of all Taiwanese species of Geothelphusa. 
The terminology used in this study mostly follows that used by Abele (1971), $\mathrm{Ng}$ (1988), Ingle (1992), Shy (1994), and Shy et al. (1994). The measurements and abbreviations taken are shown in figs. 1-2: $\mathrm{CW} \times \mathrm{CL}$, carapace width $\times$ carapace length; G1, male first gonopods (pleopods); TLG1, total length of G1 in lateral view. The G1 was subdivided into four sections for simplicity of descriptions, i.e., section 1, terminal segment (fig. 1A); 2-4, sub-terminal segment, with section 2, the synovial membrane (SM) (fig. 1B) : SML, length of synovial membrane; SMW, width of synovial membrane; SW, width of sub-terminal segment (fig. 1C). TSW, maximal width of terminal segment from two points of view (TSW1 and TSW2) (figs. 1B, 2B2); TSL, length of terminal segment (fig. 1D); AD, apical aperture diameter of tubes, or diameter of apical opening of ejaculatory canal (fig. 1A1). In addition, we counted the rings of scales on the terminal segment of G1 in two diagonal directions $(\alpha, \beta)$, i.e., Arabic numerals represent the sequence of rings with scales counted with intersected lines in diagonal directions (fig. $2 \mathrm{C}$ ); setal types: T3, simple seta, T4, plumose seta, T11, serrate seta (fig. 2D-G); LD, mean maximum diameter of the distal part of the terminal segment, measured from the distance between the opposite sides of the longest spines (LD1 and LD2) (fig. 1A1, 2A2). For the description of the dorsal aspect of the terminal segment in a formula: setal scattered $(\mathrm{SS})=(l / s), l$ : number of long T3, $s$ : number of short T3 (fig. 2B1, 2); rings of scales (SR) $=(\alpha-\beta)$. Tip of G1 (TD) seen in ventral view of terminal segment, curved in direction with angle greater than $95^{\circ}$, curved outwards; smaller than $85^{\circ}$, inwards; and $86^{\circ}-94^{\circ}$, curved upwards (fig. 2B2). Mean diameter of the female gonopores and distance between the gonopores were also measured.

For comparing the differences in the G1 between species, the ratios (table I) used mainly follow Shy et al. (1994), and include total length of G1 divided by the carapace length of an adult male (TLG1/CL), by the sub-terminal segment width (TLG1/SW), and by the terminal segment length (TLG1/TSL); the apical opening of the diameter of the ejaculatory canal and the largest diameter of the distal part of the terminal segment divided by the largest width of that segment, (AD/TSW) and (LD/TSW), respectively; and the length of the synovial membrane divided by that membrane's width (SML/SMW). The mean gonopore diameter (= (gonopore length + gonopore width)/2) divided by the carapace width of the adult female (GD/CW) was also calculated. Three body-size groups of adult male Geothelphusa were recognized: $\mathrm{CW}>30 \mathrm{~mm}$, large (group L); 22-30 mm, medium (group M); and $<22 \mathrm{~mm}$, small (group S), all after Shy (1994). 


\section{TABLE I}

A comparative survey of the micro-structures of the first gonopod (G1) in dorsal aspect observed with the SEM on topotypes of freshwater crabs of the genus Geothelphusa Stimpson, 1858 from Taiwan; character ratios and abbreviations of terms are described in the text

Species

Character

Body TLG1 TLG1 TLG1 AD/ LD/ SML/ $\mathrm{SR}$ SS Altitude GD/CW size $^{\mathrm{a}}$ / CL / SW / TSL TSW TSW SMW of habitat $(\times 100)$

(m)

\begin{tabular}{lccccccccccc}
\hline G. albogilva & $\mathrm{L}$ & 0.33 & 3.3 & 6.5 & 0.20 & 0.46 & 4.2 & $7-11$ & $4 / 26$ & 100 & 5.79 \\
G. ancylophallus & $\mathrm{L}$ & 0.30 & 2.4 & 3.5 & 0.14 & 0.56 & 2.9 & $10-11$ & $4 / 41$ & 150 & 5.72 \\
G. bicolor & $\mathrm{M}$ & 0.34 & 2.1 & 5.2 & 0.16 & 0.49 & 3.5 & $10-11$ & $12 / 34$ & $100-600$ & 7.98 \\
G. caesia & $\mathrm{L}$ & 0.35 & 3.5 & 5.3 & 0.17 & 0.45 & 3.8 & $5-7$ & $3 / 31$ & $100-500$ & 7.36 \\
G. cinerea & $\mathrm{M}$ & 0.30 & 3.1 & 4.9 & 0.16 & 0.46 & 2.8 & $8-10$ & $5 / 31$ & $100-600$ & 8.31 \\
G. dolichopodes & $\mathrm{M}$ & 0.33 & 5.6 & 8.1 & 0.15 & 0.65 & 2.9 & $9-10$ & $9 / 26$ & 500 & 7.50 \\
G. eucrinodonta & $\mathrm{S}$ & 0.35 & 2.5 & 5.9 & 0.12 & 0.40 & 3.0 & $6-8$ & $11 / 18$ & 50 & 8.44 \\
G. eurysoma & $\mathrm{S}$ & 0.27 & 5.3 & 5.3 & 0.10 & 0.72 & 2.3 & $4-5$ & $7 / 21$ & 1000 & 7.29 \\
G. gracilipes & $\mathrm{S}$ & 0.28 & 3.2 & 5.3 & 0.16 & 0.85 & 3.7 & $7-8$ & $9 / 28$ & $500-1000$ & 7.45 \\
G. ilan & $\mathrm{M}$ & 0.29 & 2.3 & 6.0 & 0.17 & 0.59 & 3.2 & $6-7$ & $10 / 36$ & $300-600$ & 8.65 \\
G. lanyu & $\mathrm{S}$ & 0.34 & 2.8 & 5.5 & 0.13 & 0.46 & 3.0 & $5-6$ & $2 / 23$ & 50 & 9.70 \\
G. lutao & $\mathrm{S}$ & 0.32 & 2.4 & 5.0 & 0.15 & 0.49 & 2.7 & $5-7$ & $4 / 34$ & 50 & 7.65 \\
G. monticola & $\mathrm{S}$ & 0.33 & 2.2 & 4.7 & 0.17 & 0.60 & 2.8 & $4-5$ & $4 / 19$ & $1500-2000$ & 8.48 \\
G. nanao & $\mathrm{M}$ & 0.33 & 2.8 & 8.4 & 0.18 & 0.53 & 3.5 & $8-9$ & $3 / 27$ & 700 & 7.92 \\
G. nanhsi & $\mathrm{M}$ & 0.36 & 3.2 & 6.6 & 0.14 & 0.37 & 4.4 & $14-15$ & $5 / 27$ & $100-200$ & 8.89 \\
G. olea & $\mathrm{L}$ & 0.30 & 2.3 & 5.1 & 0.12 & 0.48 & 2.8 & $10-11$ & $3 / 29$ & $150-1000$ & 7.62 \\
G. takuan & $\mathrm{S}$ & 0.36 & 2.4 & 5.8 & 0.13 & 0.65 & 2.9 & $6-7$ & $13 / 20$ & 1500 & 7.28 \\
G. tali & $\mathrm{S}$ & 0.31 & 3.1 & 4.9 & 0.15 & 0.53 & 3.9 & $5-6$ & $3 / 30$ & $100-300$ & 9.74 \\
G. taroko & $\mathrm{M}$ & 0.31 & 2.7 & 6.5 & 0.28 & 0.77 & 4.3 & $6-8$ & $6 / 17$ & 850 & 8.61 \\
G. tawu & $\mathrm{S}$ & 0.34 & 3.3 & 5.3 & 0.13 & 0.43 & 2.7 & $5-6$ & $5 / 23$ & 100 & 7.94 \\
G. tsayae & $\mathrm{M}$ & 0.32 & 3.0 & 6.8 & 0.11 & 0.35 & 3.7 & $10-11$ & $3 / 19$ & $100-1000$ & 7.09 \\
G. wutai & $\mathrm{M}$ & 0.40 & 4.2 & 8.3 & 0.11 & 0.39 & 4.0 & $11-11$ & $2 / 22$ & 500 & 7.18 \\
\hline
\end{tabular}

a Adult male crabs have been divided into three body-size groups according to carapace width $(\mathrm{CW})>30 \mathrm{~mm}=\operatorname{large}(\mathrm{L}) ; 22-30 \mathrm{~mm}=\operatorname{medium}(\mathrm{M}) ;<22 \mathrm{~mm}=$ small $(\mathrm{S})$; after Shy (1994).

${ }^{\mathrm{b}}$ Female character: mean gonopore diameter $(\mathrm{GD})=$ (gonopore length + gonopore width) $/ 2$, relative to carapace width.

\section{RESULTS}

Main micromorphological characteristics of the male G1 under SEM

\section{Genus Geothelphusa Stimpson, 1858}

In this genus, the main micromorphological characteristics of the male G1 using SEM were found to be as follows. The total length of G1 (TLG1) is about one-third of the carapace length of an adult male. The terminal segment was slender, and equipped with T3 setae, the numbers of short T3 being higher than those of long 
T3 setae, and the distal part equipped with 4-18 rings of scales. The sub-terminal segment is broadened, with a near by quadrangular synovial membrane and a tooth (protuberance) on the proximal outer margin. The proximal margin and the base of the sub-terminal segment have T3, T4, and T11 setae, and on the inner margin the T4 setae are more densely distributed than on the outer margin (fig. 1C-F).

\section{Geothelphusa albogilva Shy, Ng \& Yu, 1994}

$$
\text { (fig. 3A1-3) }
$$

Material examined with SEM. - Male $(29.3 \times 23.8 \mathrm{~mm})($ NSYSU F90121502): TLG1 = 7.8 $\mathrm{mm} ; \mathrm{AD}=83 \mu \mathrm{m} ; \mathrm{LD}=196.1 \mu \mathrm{m} ; \mathrm{SR}=7-11 ; \mathrm{SS}=4 / 26 ; \mathrm{TD}=116^{\circ}$; Bauli, Hengchun, Pingtung county, coll. W.-J. Chen, 15 Dec. 2001.

Other material. - Two males, 2 juveniles (largest male $40.6 \times 31.9 \mathrm{~mm}$ ) (NSYSU F90121507), Bauli, Hengchun, Pingtung county, coll. W.-J. Chen, 15 Dec. 2001; 2 males (largest $38.8 \times 32.3 \mathrm{~mm}$ ) (NSYSU F90071201), Hengchun, Pingtung county, coll. W.-J. Chen, 12 July 2001; 1 male, 1 female (male $33.7 \times 26.8$ mm) (NSYSU F89111401), Tajen, Taitung county, coll. W.-J. Chen, 14 Nov. 2000; 1 female, 1 juvenile (female $36.0 \times 26.4$ mm) (NSYSU F90120801), Mutan, Pingtung county, coll. W.-J. Chen, 8 Dec. 2001.

Terminal segment. - Curved outwards and reaching beyond sternal condyle in situ, distal part with 7-11 rings of scales (fig. 3A1) and a maximum diameter of $196.1 \mu \mathrm{m}$; dorsal aspect of terminal segment with 4 long T3 setae and 26 short T3 setae (fig. 3A2); diameter of apical opening of ejaculatory canal about $83.0 \mu \mathrm{m}$; length and width of base about $1.2 \mathrm{~mm}$ and $422.7 \mu \mathrm{m}$, respectively.

Sub-terminal segment. - Mean width about $2.4 \mathrm{~mm}$; with synovial membrane of which ratio length : width is about 4.2 , basal margin low, concave and top margin rather convex (fig. 3A3); with one protuberance on proximal outer angle. Proximal margin and base of sub-terminal segment with setae, inner margin with T4 setae clustered mainly on section 4 and more densely distributed than on outer margin, the setae of which barely reach sections 3-4.

Female gonopores. - Diameter 2.6-2.8 $\times$ 1.8-1.9 mm, distance between pores approx. $2.2 \mathrm{~mm}$.

\section{Geothelphusa ancylophallus Shy, $\mathrm{Ng} \& \mathrm{Yu}, 1994$}

$$
\text { (fig. 3B1-3) }
$$

Material examined with SEM. - Male $(33.5 \times 26.3 \mathrm{~mm})($ NSYSU F89110401): TLG1 = 8.0 $\mathrm{mm} ; \mathrm{AD}=75.6 \mu \mathrm{m} ; \mathrm{LD}=298.7 \mu \mathrm{m} ; \mathrm{SR}=10-11 ; \mathrm{SS}=4 / 41 ; \mathrm{TD}=107^{\circ} ;$ Neimen, Kaohsiung county, coll. W.-J. Chen, 4 Nov. 2000; 1 male $(35.5 \times 28.7 \mathrm{~mm})($ NSYSU F90112404), Neimen, Kaohsiung county, coll. W.-J. Chen, 24 Nov. 2001.

Other material. - One male $(33.1 \times 26.7$ mm) (NSYSU F89110402), Neimen, Kaohsiung county, coll. W.-J. Chen, 4 Nov. 2000; 2 males (largest $32.0 \times 24.9$ mm) (NSYSU F91050101), Lungchi, Tainan county, coll. W.-J. Chen, 1 May 2002; 2 females (largest 37.6×30.5 mm) (NSYSU F910222), Chishan, Kaohsiung county, coll. W.-J. Chen, 22 Feb. 2002; 1 female $(31.4 \times 25.0 \mathrm{~mm})(\mathrm{NSYSU}$ F920622), Tienliao, Kaohsiung county, coll. W.-J. Chen, 22 June 2003. 


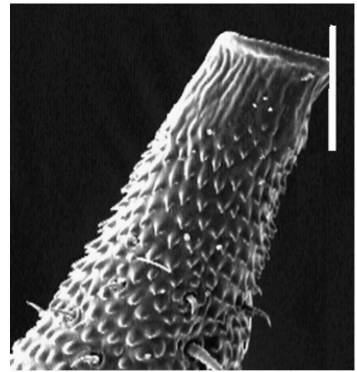

A1

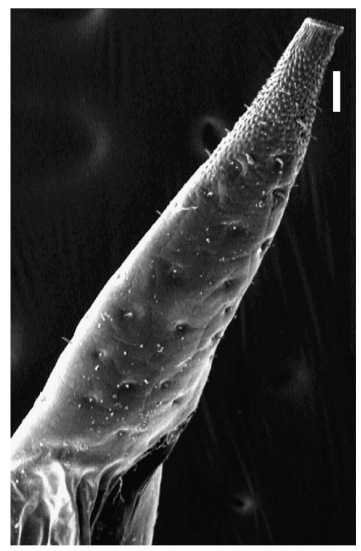

A2

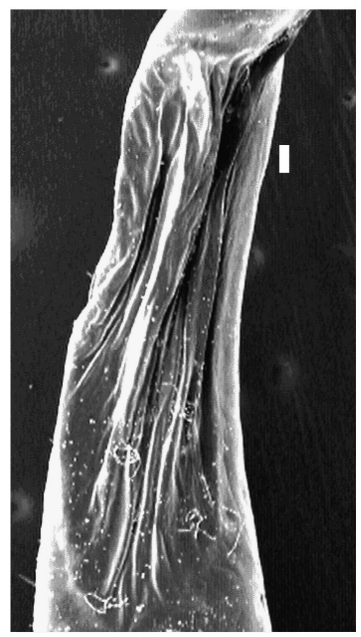

A3

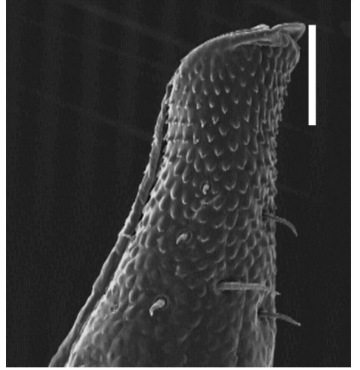

B1

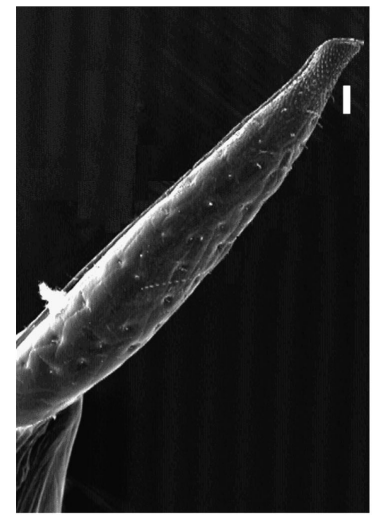

\section{B2}

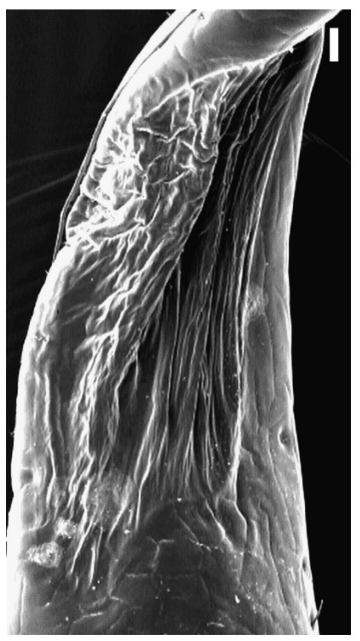

B3

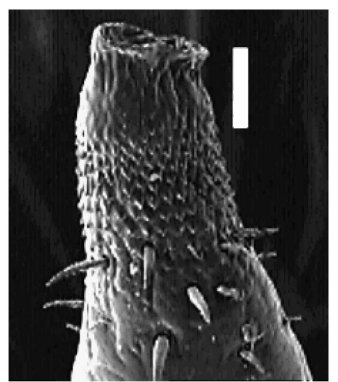

\section{C1}

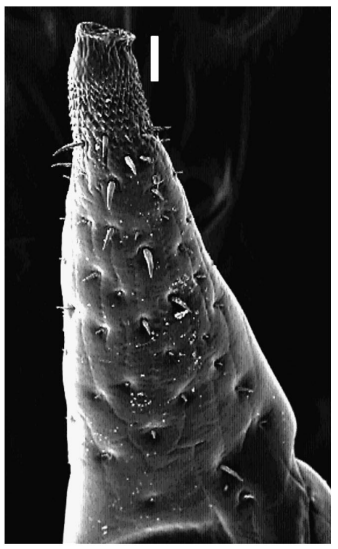

C2

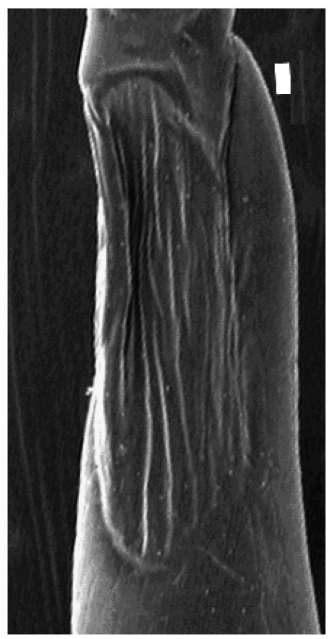

C3

Fig. 3. Micromorphology of the right G1 of freshwater crabs of the genus Geothelphusa Stimpson, 1858 by SEM. A, G. albogilva Shy, Ng \& Yu, 1994, $29.3 \times 23.8$ mm (NSYSU F90121502); B, G. ancylophallus Shy, Ng \& Yu, 1994, $33.5 \times 26.3$ mm (NSYSU F89110401); C, G. bicolor Shy, Ng $\& \mathrm{Yu}, 1994,29.4 \times 22.8 \mathrm{~mm}$ (NSYSU F90070301B); 1, dorsal view of terminal segment, distal part magnified; 2, dorsal view of terminal segment; 3, synovial membrane. Scales: $100 \mu \mathrm{m}$. 
Terminal segment. - Curved outwards and reaching slightly beyond sternal condyle in situ, distal part with 10-11 rings of scales (fig. 3B1) and a mean maximum diameter of $261.9 \mu \mathrm{m}$; dorsal aspect of terminal segment with 4 long T3 setae and 41 short T3 setae (fig. 3B2); diameter of apical opening of ejaculatory canal about $75.6 \mu \mathrm{m}$; length and width of base about $2.3 \mathrm{~mm}$ and $529.2 \mu \mathrm{m}$, respectively.

Sub-terminal segment. - Mean width about $3.3 \mathrm{~mm}$; with synovial membrane of which ratio length : width is about 2.9, basal margin low, broad, concave with a faint v-shape and top margin oblique (fig. 3B3); with one protuberance on proximal outer angle. Proximal margin and base of sub-terminal segment with setae, inner margin with T4 setae clustered on sections 3-4 and more densely distributed than on outer margin, the setae of which barely reach sections 3-4.

Female gonopores. - Diameter 2.1-2.3 × 1.8-2.0 mm, distance between pores approx. 1.6-2.1 mm.

\section{Geothelplusa bicolor Shy, Ng \& Yu, 1994}

(fig. 3C1-3)

Material examined with SEM. - Male $(29.4 \times 22.8 \mathrm{~mm})($ NSYSU F90070301B): TLG1 = 7.8 $\mathrm{mm} ; \mathrm{AD}=85.2 \mu \mathrm{m} ; \mathrm{LD}=265.3 \mu \mathrm{m} ; \mathrm{SR}=10-11 ; \mathrm{SS}=12 / 34 ; \mathrm{TD}=132^{\circ} ;$ Yenping, Taitung county, coll. W.-J. Chen \& Z.-S. Sun, 3 July 2001. Male $(26.0 \times 20.6 \mathrm{~mm})($ NSYSU F90070301), Yenping, Taitung county, coll. W.-J. Chen \& Z.-S. Sun, 3 July 2001.

Other material. - Two males, 2 females (largest female $29.4 \times 23.0 \mathrm{~mm}$ ) (NSYSU F91092102), Taimali, Taitung county, coll. W.-J. Chen, 21 Sept. 2002; 1 female $(31.2 \times 23.5 \mathrm{~mm})$ (NSYSU F891114), Taimali, Taitung county, coll. W.-J. Chen, 14 Nov. 2000; 2 males, 1 female (largest male $33.2 \times 25.3 \mathrm{~mm})($ NSYSU F891114B), Taimali, Taitung county, coll. W.-J. Chen, 14 Nov. 2000.

Terminal segment. - Curved outwards and reaching slightly below sternal condyle in situ, distal part with 10-11 rings of scales (fig. 3C1) and a mean maximum diameter of $245.2 \mu \mathrm{m}$; dorsal aspect of terminal segment with 12 long T3 setae and 34 short T3 setae (fig. 3C2); diameter of apical opening of ejaculatory canal about $85.2 \mu \mathrm{m}$; length and width of base about $1.5 \mathrm{~mm}$ and $542 \mu \mathrm{m}$, respectively.

Sub-terminal segment. - Mean width about $3.7 \mathrm{~mm}$; with synovial membrane of which ratio length : width is about 3.5, basal margin broad, concave and top margin convex (fig. 3C3); with one protuberance on proximal outer angle. Proximal margin and base of sub-terminal segment with setae, inner margin with T4 setae clustered mainly on section 4 and more densely distributed than on outer margin, the setae of which barely reach section 4 .

Female gonopores. - Diameter 3.0-3.4 × 1.4-1.9 mm, distance between pores approx. $1.9-2.5 \mathrm{~mm}$. 
Geothelphusa caesia Shy, Ng \& Yu, 1994

(fig. 4A1-3)

Material examined with SEM. - Male $(30.3 \times 24.3 \mathrm{~mm})($ NSYSU F91052507): TLG1 = 8.4 $\mathrm{mm} ; \mathrm{AD}=89.6 \mu \mathrm{m} ; \mathrm{LD}=242.4 \mu \mathrm{m} ; \mathrm{SR}=5-7 ; \mathrm{SS}=3 / 31 ; \mathrm{TD}=118^{\circ}$; Liukuei, Kaohsiung county, coll. W.-J. Chen, 25 May 2002; 1 male $(28.7 \times 22.4$ mm) (NSYSU F89092301), Meinung, Kaohsiung county, coll. W.-J. Chen, 23 Sept. 2000.

Other material. — One female $(37.2 \times 29.9 \mathrm{~mm})$ (NSYSU F89092302), Meinung, Kaohsiung county, coll. W.-J. Chen, 23 Sept. 2000; 1 male $(30.2 \times 23.1 \mathrm{~mm})($ NSYSU F91010501), Liukuei, Kaohsiung county, coll. W.-J. Chen, 5 Jan. 2002; 2 males (largest $29.2 \times 23.2 \mathrm{~mm}$ ) (NSYSU F9007170603), Chiahsien, Kaohsiung county, coll. W.-J. Chen, 17 July 2001; 1 male, 1 female (male $33.3 \times 25.8$ mm) $($ NSYSU F89092302), Meinung, Kaohsiung, coll. W.-J. Chen, 23 Sept. 2000.

Terminal segment. - Curved outwards and reaching below sternal condyle in situ, distal part with 5-8 rings of scales (fig. 4A1) and a mean maximum diameter of $227.9 \mu \mathrm{m}$; dorsal aspect of terminal segment with 3 long T3 setae and 31-32 short T3 setae (fig. 4A2); diameter of apical opening of ejaculatory canal about $89.6 \mu \mathrm{m}$; length and width of base about $1.6 \mathrm{~mm}$ and $540.5 \mu \mathrm{m}$, respectively.

Sub-terminal segment. - Mean width about $2.4 \mathrm{~mm}$; with synovial membrane of which ratio length : width is about 3.8, base margin low, concave with a faint vshape and top margin convex (fig. 4A3); with a indistinct protuberance on proximal outer angle. Proximal margin and base of sub-terminal segment with setae, inner margin with T4 setae clustered mainly on sections 3-4 and more densely distributed than on outer margin, the setae of which barely reach section 4 .

Female gonopores. - Diameter 3.0 $\times$ 2.1-2.4 mm, distance between pores approx. $2.9 \mathrm{~mm}$.

Geothelphusa cinerea Shy, Ng \& Yu, 1994

(fig. 4B1-3)

Material examined with SEM. - Male $(29.0 \times 22.9 \mathrm{~mm})($ NSYSU F90070310): TLG1 = 6.8 $\mathrm{mm} ; \mathrm{AD}=85.5 \mu \mathrm{m} ; \mathrm{LD}=252.7 \mu \mathrm{m} ; \mathrm{SR}=8-10 ; \mathrm{SS}=5 / 31 ; \mathrm{TD}=101^{\circ} ;$ Lichi, Taitung county, coll. W.-J. Chen \& Z.-S. Sun, 3 July 2001; 1 male $(29.4 \times 23.1$ mm) (NSYSU F9107010102), Lichi, Taitung county, coll. W.-J. Chen \& Z.-S. Sun, 1 July 2002.

Other material. - One female $(30.3 \times 23.1 \mathrm{~mm})$ (NSYSU F90070310), Lichi, Taitung county, coll. W.-J. Chen \& Z.-S. Sun, 3 July 2001; 2 males (largest $27.9 \times 22.1 \mathrm{~mm})($ NSYSU F91020325), Kuanshan, Taitung county, coll. W.-J. Chen \& Z.-S. Sun, 3 Feb. 2002; 1 male, 1 female (female $31.3 \times 24.3 \mathrm{~mm}$ ) (NSYSU F90070309B), Lichi, Taitung county, coll. W.-J. Chen \& Z.-S. Sun, 3 July 2001 .

Terminal segment. - Curved outwards and reaching nearly to sternal condyle in situ, distal part with 8-10 rings of scales (fig. 4B1) and a maximum diameter of $252.7 \mu \mathrm{m}$; dorsal aspect of terminal segment with 5 long T3 setae and 31 short T3 setae (fig. 4B2); diameter of apical opening of ejaculatory canal about $85.5 \mu \mathrm{m}$; length and width of base about $1.4 \mathrm{~mm}$ and $545.5 \mu \mathrm{m}$, respectively. 


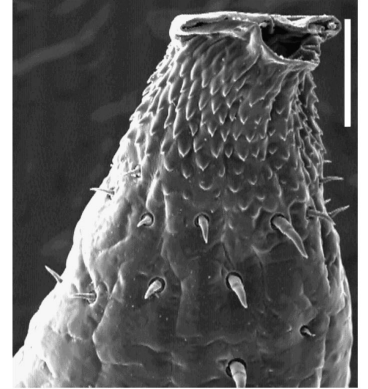

A1

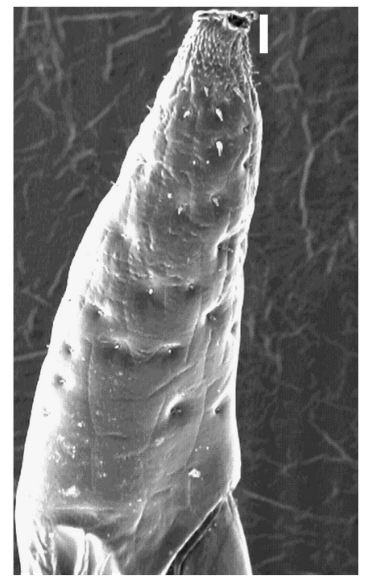

A2

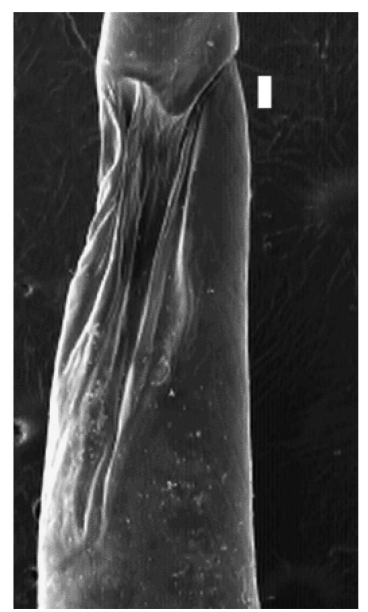

A3

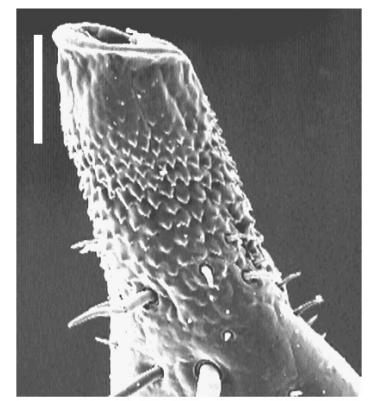

\section{B1}

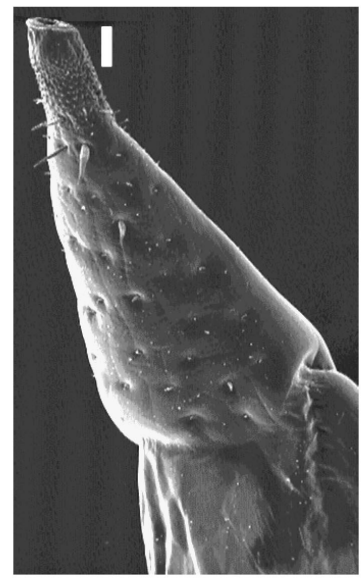

B2

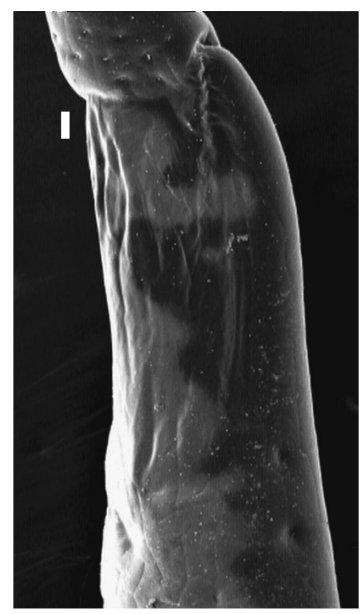

B3

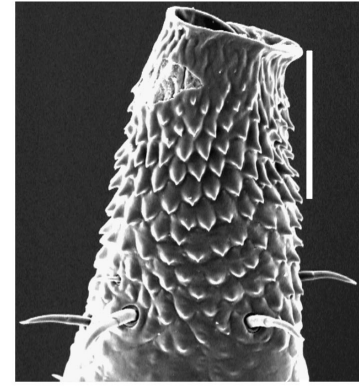

C1

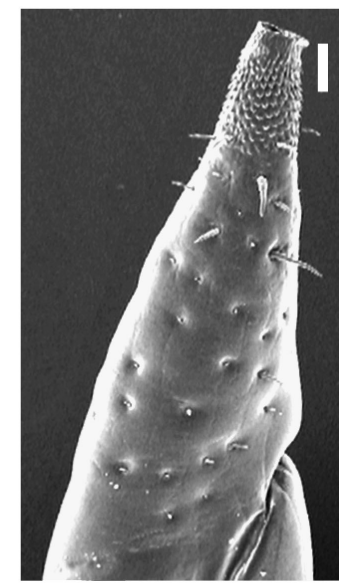

$\mathrm{C} 2$

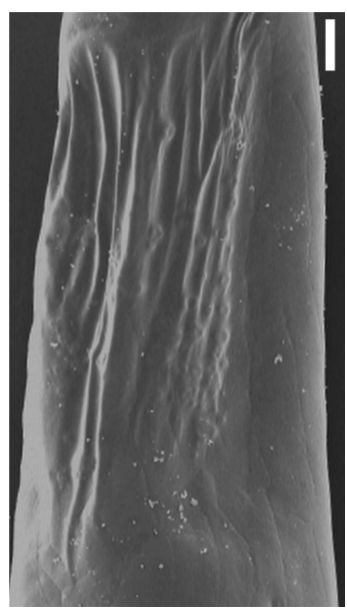

C3

Fig. 4. Micromorphology of the right G1 of freshwater crabs of the genus Geothelphusa Stimpson, 1858 by SEM. A, G. caesia Shy, Ng \& Yu, 1994, $30.3 \times 24.3$ mm (NSYSU F91052507); B, G. cinerea Shy, Ng \& Yu, 1994, $29.0 \times 22.9$ mm (NSYSU F90070310); C, G. dolichopodes Shy, Ng $\&$ Yu, 1994, $24.3 \times 18.3 \mathrm{~mm}$ (NSYSU F89081204); 1, dorsal view of terminal segment, distal part magnified; 2, dorsal view of terminal segment; 3, synovial membrane. Scales: $100 \mu \mathrm{m}$. 
Sub-terminal segment. - Mean width about $2.2 \mathrm{~mm}$; with synovial membrane of which ratio length : width is about 2.8 , base margin broad, concave with a vshape and top margin horizontal (fig. 4B3); with one indistinct protuberance on proximal outer angle. Proximal margin and base of sub-terminal segment with setae, inner margin with T4 setae clustered mainly on section 4 and more densely distributed than on outer margin, the setae of which barely reach sections 3-4.

Female gonopores. - Diameter 3.0-3.3 × 1.8-1.9 mm, distance between pores aprox. 1.9-2.0 $\mathrm{mm}$.

Geothelphusa dolichopodes Shy, Ng \& Yu, 1994

(fig. 4C1-3)

Material examined with SEM. - Male $(24.3 \times 18.3 \mathrm{~mm})($ NSYSU F89081204): TLG1 = 6.1 $\mathrm{mm} ; \mathrm{AD}=65.8 \mu \mathrm{m} ; \mathrm{LD}=276.7 \mu \mathrm{m} ; \mathrm{SR}=9-10 ; \mathrm{SS}=9 / 26 ; \mathrm{TD}=125^{\circ} ;$ Hsiulin, Hwalien county, coll. W.-J. Chen \& J.-Y. Shy, 12 Aug. 2000.

Other material. - Two males, 1 female $(24.0 \times 18.9 \mathrm{~mm})$ (NSYSU F89081205), Hsiulin, Hwalien county, coll. W.-J. Chen \& J.-Y. Shy, 12 Aug., 2000.

Terminal segment. - Curved outwards and reaching slightly below sternal condyle in situ, distal part with 9-10 rings of scales (fig. 4C1) and a mean maximum diameter of $266.0 \mu \mathrm{m}$; dorsal aspect of terminal segment with 9 long T3 setae and 26 short T3 setae (fig. 4C2); diameter of apical opening of ejaculatory canal about $65.8 \mu \mathrm{m}$; length and width of base about $1.1 \mathrm{~mm}$ and $427.7 \mu \mathrm{m}$, respectively.

Sub-terminal segment. - Width about $1.1 \mathrm{~mm}$; with synovial membrane of which ratio length : width is about 2.9 , basal margin $\mathrm{v}$-shape and top margin oblique (fig. 4C3); with one protuberance on proximal outer angle. Proximal margin and base of sub-terminal segment with setae, inner margin with T4 setae clustered on sections 3-4 and more densely distributed than on outer margin, the setae of which barely reach section 4 .

Female gonopores. - Diameter 2.1-2.3 × 1.2-1.3 mm, distance between pores approx. $1.8 \mathrm{~mm}$.

Geothelphusa eucrinodonta Shy, Ng \& Yu, 1994

(figs. 1-2)

Material examined with SEM. - Male $(15.3 \times 11.9 \mathrm{~mm})($ NSYSU F710041): TLG1 = $4.1 \mathrm{~mm}$; $\mathrm{AD}=55.8 \mu \mathrm{m} ; \mathrm{LD}=188.3 \mu \mathrm{m} ; \mathrm{SR}=6-8 ; \mathrm{SS}=11 / 18$; $\mathrm{TD}=120^{\circ}$; Kungliao, Homei, Taipei county, coll. W.-J. Chen \& C.-F. Tseng, 10 July 2003.

Other material. - One male, 1 female $(17.5 \times 13.0 \mathrm{~mm})(\mathrm{NSYSU}$ F81501), Kungliao, Homei, Taipei county, coll. W.-J. Chen \& J.-Y. Shy, 15 Aug. 2001; 1 male, 1 female $(23.2 \times 19.3 \mathrm{~mm})$ (NSYSU F710042), Kungliao, Homei, Taipei county, coll. W.-J. Chen \& C.-F. Tseng, 10 July 2003.

Terminal segment. - Curved outwards and reaching below sternal condyle in situ, distal part with 6-8 rings of scales (fig. 2C) and a mean maximum diameter of 
$183.5 \mu \mathrm{m}$; dorsal aspect of terminal segment with 11 long T3 setae and 18 short T3 setae (fig. 1A); diameter of apical opening of ejaculatory canal about $55.8 \mu \mathrm{m}$ (fig. 1A1); length and width of base about $0.7 \mathrm{~mm}$ and $466.2 \mu \mathrm{m}$, respectively.

Sub-terminal segment. - Width about $1.65 \mathrm{~mm}$; with synovial membrane of which ratio length : width is about 3.0, basal margin v-shape and top margin horizontal (fig. 1B); with one protuberance on proximal outer angle. Proximal margin and base of sub-terminal segment with setae, inner margin with T4 setae clustered on section 4 and more densely distributed than on outer margin, the setae of which barely reach section 2 (fig. 1D-F).

Female gonopores. - Diameter 2.2-2.3 × 1.5-1.6 mm, distance between pores approx. 1.5-1.9 mm.

Geothelphusa eurysoma Shy, Ng \& Yu, 1994 (fig. 5A1-3)

Material examined with SEM. - Male $(21.8 \times 15.8 \mathrm{~mm})($ NTOU F10110), left G1: TLG1 $=4.2$ $\mathrm{mm} ; \mathrm{AD}=32.2 \mu \mathrm{m} ; \mathrm{LD}=225.2 \mu \mathrm{m} ; \mathrm{SR}=4-5 ; \mathrm{SS}=7 / 21 ; \mathrm{TD}=60^{\circ}$; Chingshan, Hoping, Taichung county, coll. J.-Y. Shy \& K. Lee, 19 Oct. 1992.

Other material. - Two females (largest $19.2 \times 14.4 \mathrm{~mm}$ ) (NTOU F10111), Chingshan, Hoping, Taichung county, coll. J.-Y. Shy \& K. Lee, 19 Oct. 1992.

Terminal segment. - Curved inwards, distal part with 4-5 rings of scales (fig. 5A1) and a mean maximum diameter of $211.5 \mu \mathrm{m}$; dorsal aspect of terminal segment with 7 long T3 setae and 21 short T3 setae (fig. 5A2); diameter of apical opening of ejaculatory canal about $32.2 \mu \mathrm{m}$; length and width of base about 0.8 $\mathrm{mm}$ and $313.0 \mu \mathrm{m}$, respectively.

Sub-terminal segment. - Mean width about $0.8 \mathrm{~mm}$; with synovial membrane of which ratio length : width is about 2.3, basal margin low, broad, concave and top margin oblique (fig. 5A3); without conspicuous protuberance on proximal outer angle. Proximal margin and base of sub-terminal segment with setae, inner margin with T4 setae clustered on section 4 and more densely distributed than on outer margin, the setae of which barely reach sections 3-4.

Female gonopores. - Diameter 1.5-1.7 × 1.0-1.1 mm, distance between pores approx. $0.9 \mathrm{~mm}$.

Geothelphusa gracilipes Shy, Ng \& Yu, 1994 (fig. 5B1-3)

Material examined with SEM. - Male $(23.4 \times 19.0 \mathrm{~mm})($ NSYSU F7030101): TLG1 = $5.3 \mathrm{~mm}$; $\mathrm{AD}=42.9 \mu \mathrm{m} ; \mathrm{LD}=228.2 \mu \mathrm{m} ; \mathrm{SR}=7-8 ; \mathrm{SS}=9 / 28 ; \mathrm{TD}=118^{\circ}$; Hsiulin, Lushui, Hwalien county, coll. W.-J. Chen \& Z.-S. Sun, 3 July 2002; 1 male $(19.12 \times 14.2 \mathrm{~m})($ NSYSU F89081201), $\mathrm{TLG} 1=5.5 \mathrm{~mm} ; \mathrm{AD}=43.0 \mu \mathrm{m} ; \mathrm{LD}=152.1-189.7 \mu \mathrm{m} ; \mathrm{SR}=7-8 ; \mathrm{SS}=12 / 23 ; \mathrm{TD}=108^{\circ}$;

Hsiulin, Lushui, Hwalien county, coll. W.-J. Chen \& J.-Y. Shy, 2 Aug. 2000. 

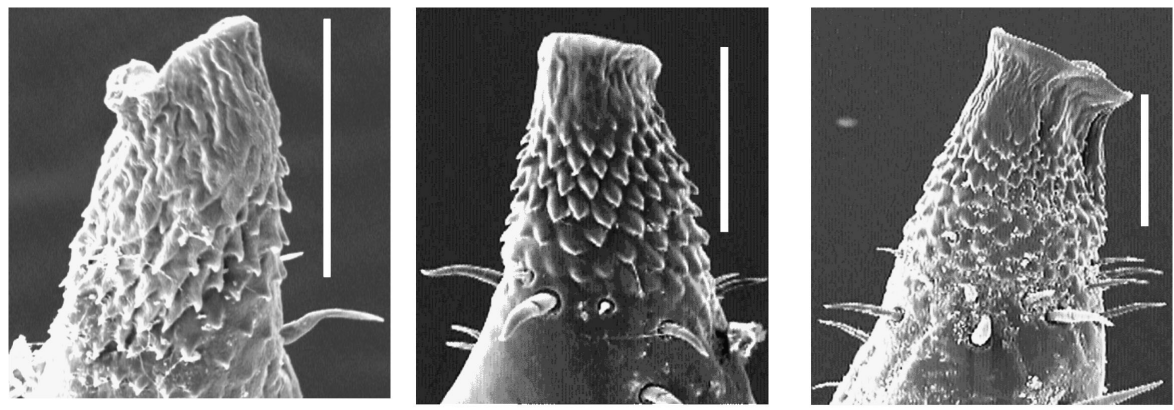

A1

\section{B1}

\section{C1}
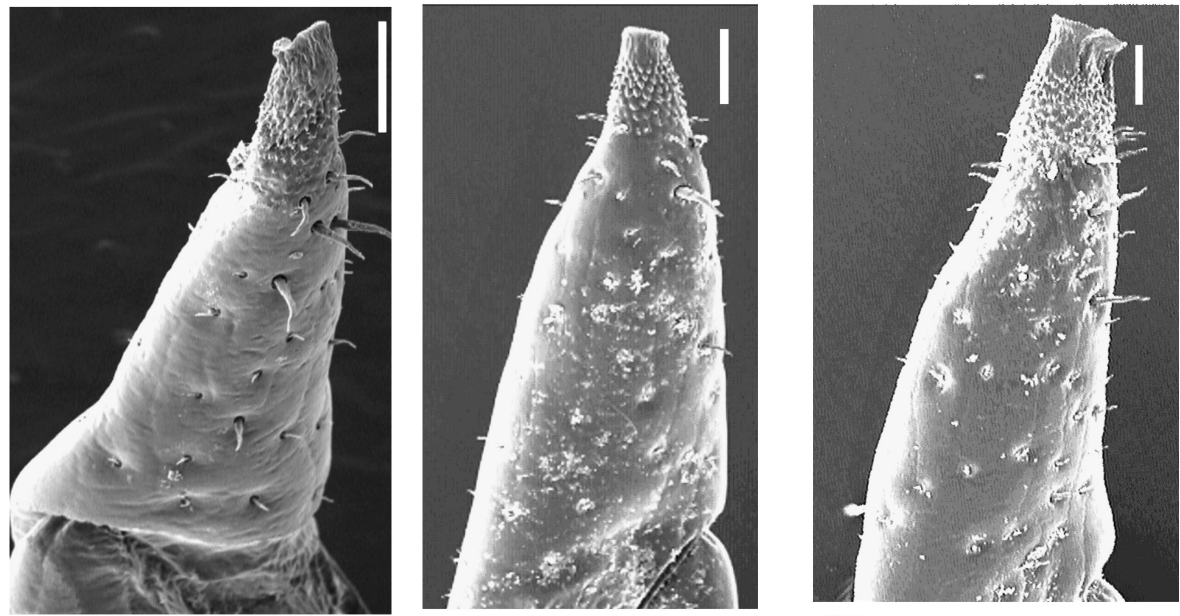

$\mathrm{C2}$

A2

B2

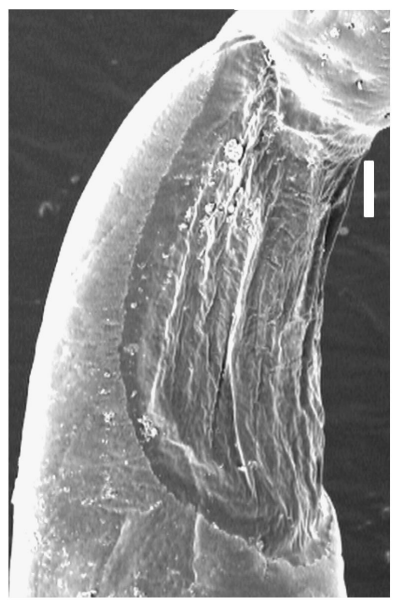

A3

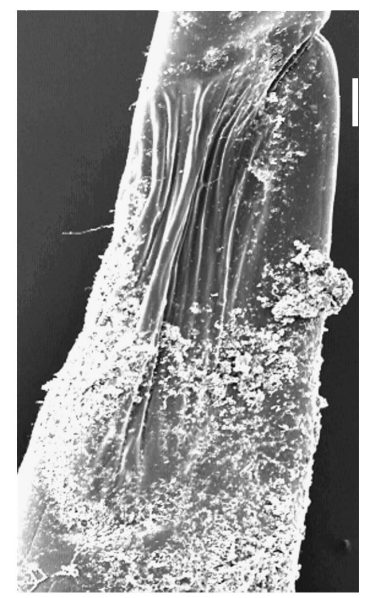

B3

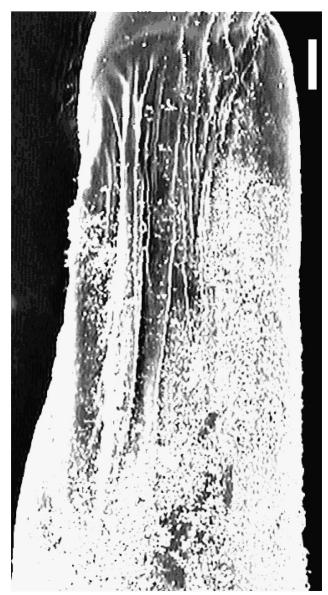

C3

Fig. 5. Micromorphology of the right G1 of freshwater crabs of the genus Geothelphusa Stimpson, 1858 by SEM. A, G. eurysoma Shy, Ng \& Yu, 1994, $21.8 \times 15.8$ mm (NTOU F10110) (left G1); B, G. gracilipes Shy, Ng \& Yu, 1994, $23.4 \times 19.0$ mm (NSYSU F7030101); C, G. ilan Shy, Ng \& Yu, 1994, $26.3 \times 20.9 \mathrm{~mm}$ (NSYSU F92022801); 1, dorsal view of terminal segment, distal part magnified; 2, dorsal view of terminal segment; 3, synovial membrane. Scales: $100 \mu \mathrm{m}$. 
Other material. - One male, 1 female $(21.5 \times 16.2 \mathrm{~mm})$ (NSYSU F89081202), Hsiulin, Lushui, Hwalien county, coll. W.-J. Chen \& J.-Y. Shy, 2 Aug. 2000; 1 male, 1 female $(23.5 \times 17.5 \mathrm{~mm})$ (NSYSU F7030102), Hsiulin, Lushui, Hwalien county, coll. W.-J. Chen \& Z.-S. Sun, 3 July 2002.

Terminal segment. - Curved inwards and reaching slightly beyond sternal condyle in situ, distal part with 7-8 rings of scales (fig. 5B1) and a mean maximum diameter of $192.4 \mu \mathrm{m}$; dorsal aspect of terminal segment with 9-12 long T3 setae and 23-28 short T3 setae (fig. 5B2); diameter of apical opening of ejaculatory canal about $43 \mu \mathrm{m}$; length and width of base about $1 \mathrm{~mm}$ and $270 \mu \mathrm{m}$, respectively.

Sub-terminal segment. - Mean width about $1.65 \mathrm{~mm}$; with synovial membrane of which ratio length : width is about 3.7-5.0, basal margin in arc shape and top margin oblique (fig. 5B3); with one protuberance on proximal outer angle. Proximal margin and base of sub-terminal segment with setae, inner margin with T4 setae clustered on sections 3-4 and more densely distributed than on outer margin, the setae of which barely reach section 3 .

Female gonopores. - Diameter 2.1 × 1.1-1.4 mm, distance between pores approx. 1.1-1.6 mm.

Geothelphusa ilan Shy, Ng \& Yu, 1994

(fig. 5C1-3)

Material examined with SEM. - Male $(26.3 \times 20.9 \mathrm{~mm})($ NSYSU F92022801): TLG1 = 6.0 $\mathrm{mm} ; \mathrm{AD}=76.4 \mu \mathrm{m} ; \mathrm{LD}=260.7 \mu \mathrm{m} ; \mathrm{SR}=6-7 ; \mathrm{SS}=10 / 36$; $\mathrm{TD}=127^{\circ}$; Tatung, Lunpi, Ilan county, coll. W.-J. Chen \& Z.-S. Sun, 28 Feb. 2003.

Other material. - Five females (largest $28.9 \times 22.8 \mathrm{~mm}$ ) (NSYSU F90081503), Tatung, Lunpi, Ilan county, coll. W.-J. Chen \& J.-Y. Shy, 15 Aug. 2001; 2 males (largest $25.1 \times 19.6$ mm) (NSYSU F920228012), Tatung, Insu, Ilan county, coll. W.-J. Chen \& Z.-S. Sun, 28 Feb. 2003.

Terminal segment. - Curved outwards and reaching below sternal condyle in situ, distal part with 6-7 rings of scales (fig. 5C1) and a mean maximum diameter of $243.7 \mu \mathrm{m}$; dorsal aspect of terminal segment with 10 long T3 setae and 36 short T3 setae (fig. 5C2); diameter of apical opening of ejaculatory canal about $76.4 \mu \mathrm{m}$; length and width of base about $1.0 \mathrm{~mm}$ and $445.1 \mu \mathrm{m}$, respectively.

Sub-terminal segment. - Width about $2.6 \mathrm{~mm}$; with synovial membrane of which ratio length : width is about 3.2 , basal margin slightly $\mathrm{v}$-shape and top margin oblique (fig. 5C3); with one protuberance on proximal outer angle. Proximal margin and base of sub-terminal segment with setae, inner margin with T4 setae clustered on sections 3-4 and more densely distributed than on outer margin, the setae of which barely reach sections 3-4.

Female gonopores. - Diameter $3.0 \times 2.0 \mathrm{~mm}$, distance between pores approx. $1.8 \mathrm{~mm}$. 
Geothelphusa lanyu Shy, $\mathrm{Ng} \& \mathrm{Yu}, 1994$

(fig. 6A1-3)

Material examined with SEM. - Male $(21.5 \times 16.4 \mathrm{~mm})($ NSYSU F91032301): TLG1 $=5.5$ $\mathrm{mm} ; \mathrm{AD}=51.4 \mu \mathrm{m} ; \mathrm{LD}=179.4 \mu \mathrm{m} ; \mathrm{SR}=5-6, \mathrm{SS}=2 / 23 ; \mathrm{TD}=115^{\circ} ;$ Lanyu, Taitung county, coll. W.-J. Chen \& C.-F. Tseng, 23 Mar. 2002; 1 male $(17.8 \times 13.5$ mm) (NSYSU F9103221), Lanyu, Taitung county, coll. W.-J. Chen \& C.-F. Tseng, 22 Mar. 2002.

Other material. - One male, 4 females (largest female $20.1 \times 15.6 \mathrm{~mm}$ ) (NSYSU F910322011), Lanyu, Taitung county, coll. W.-J. Chen \& C.-F. Tseng, 22 Mar. 2002; 1 female $(16.9 \times 13.0 \mathrm{~mm})$ (NSYSU F910322), Lanyu, Taitung county, coll. W.-J. Chen \& C.-F. Tseng, 22 Mar. 2002; 4 males (largest $17.6 \times 14.0 \mathrm{~mm}$ ) (NSYSU F91032302), Lanyu, Taitung county, coll. W.-J. Chen \& C.-F. Tseng, 23 Mar. 2002.

Terminal segment. - Curved outwards and reaching beyond sternal condyle in situ, distal part with 5-6 rings of scales (fig. 6A1) and a mean maximum diameter of $172.2 \mu \mathrm{m}$; dorsal aspect of terminal segment with 2 long T3 setae and 23 short T3 setae (fig. 6A2); diameter of apical opening of ejaculatory canal about $51.4 \mu \mathrm{m}$; length and width of base about $1.0 \mathrm{~mm}$ and $393.3 \mu \mathrm{m}$, respectively.

Sub-terminal segment. — Width about $2.0 \mathrm{~mm}$; with synovial membrane of which ratio length : width is about 3.0, basal margin a faint $\mathrm{v}$-shape and top margin concave (fig. 6A3); with one protuberance on proximal outer angle. Proximal margin and base of sub-terminal segment with setae, inner margin with T4 setae clustered on sections 3-4 and more densely distributed than on outer margin, the setae of which barely reach section 3 .

Female gonopores. - Diameter $2.0 \times 1.8-1.9 \mathrm{~mm}$, distance between pores approx. $1.0 \mathrm{~mm}$.

Geothelphusa lutao Shy, Ng \& Yu, 1994

(fig. 6B1-3)

Material examined with SEM. - Male $(22.3 \times 17.4 \mathrm{~mm})($ NSYSU F91112301): TLG1 = 5.5 $\mathrm{mm} ; \mathrm{AD}=68.2 \mu \mathrm{m} ; \mathrm{LD}=229.4 \mu \mathrm{m} ; \mathrm{SR}=5-7 ; \mathrm{SS}=4 / 34 ; \mathrm{TD}=115^{\circ}$; Lutao, Taitung county, coll. W.-J. Chen \& C.-F. Tseng, 23 Nov. 2002.

Other material. - Nine males, 1 female $(19.6 \times 14.6 \mathrm{~mm})$ (NSYSU F91112302), Lutao, Taitung county, coll. W.-J. Chen \& C.-F. Tseng, 23 Nov. 2002.

Terminal segment. - Curved outwards and reaching below sternal condyle in situ, distal part with 5-7 rings of scales (fig. 6B1) and a mean maximum diameter of $221.5 \mu \mathrm{m}$; dorsal aspect of terminal segment with 4 long T3 setae and 34 short T3 setae (fig. 6B2); diameter of apical opening of ejaculatory canal about $68.2 \mu \mathrm{m}$; length and width of base about $1.1 \mathrm{~mm}$ and $467.1 \mu \mathrm{m}$, respectively.

Sub-terminal segment. - Width about $2.3 \mathrm{~mm}$; with synovial membrane of which ratio length : width is about 2.7 , basal margin concave and a faint $\mathrm{v}$-shape and top margin horizontal (fig. 6B3); with one protuberance on proximal outer angle. Proximal margin and base of sub-terminal segment with setae, inner margin 


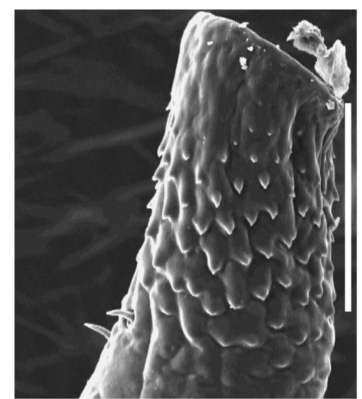

A1

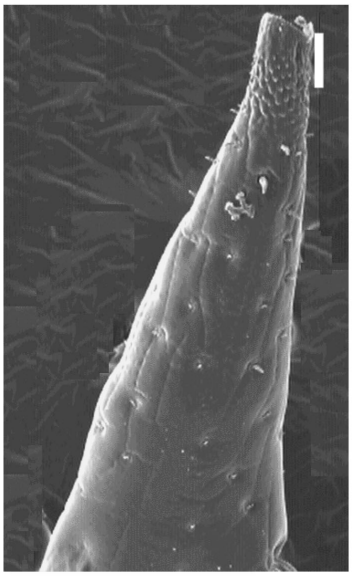

A2

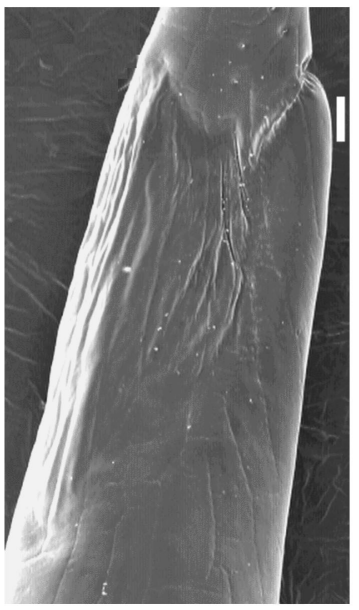

A3

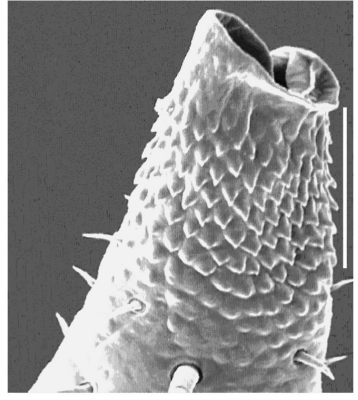

\section{B1}

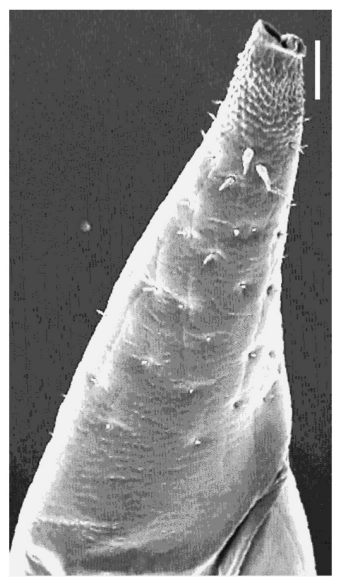

B2

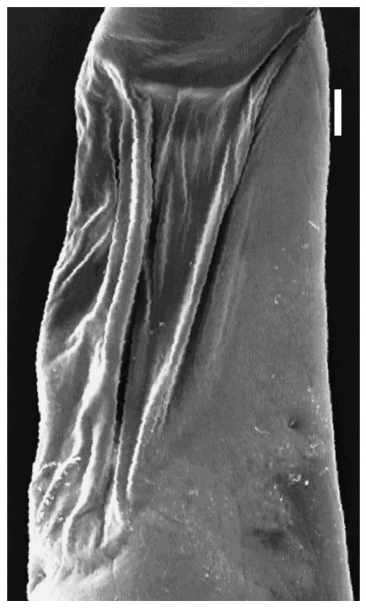

B3

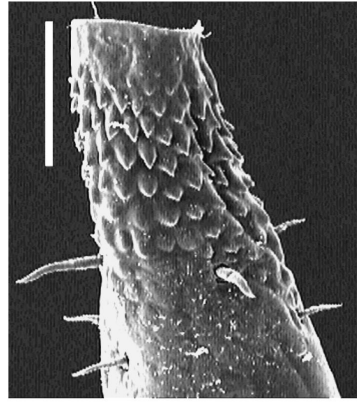

C1

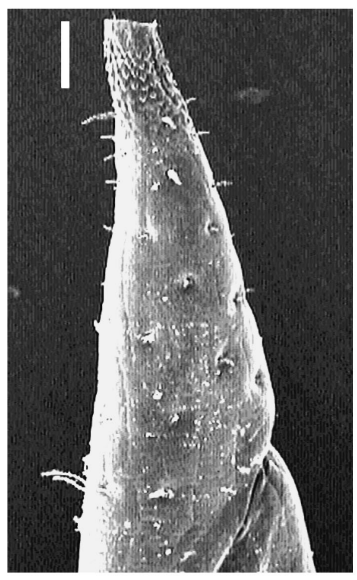

C2

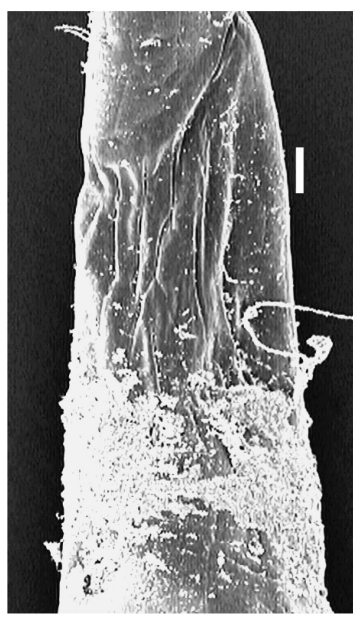

C3

Fig. 6. Micromorphology of the right G1 of freshwater crabs of the genus Geothelphusa Stimpson, 1858 by SEM. A, G. lanyu Shy, Ng \& Yu, 1994, $21.5 \times 16.4$ mm (NSYSU F91032301); B, G. lutao Shy, Ng \& Yu, 1994, 22.3 × 17.4 mm (NSYSU F91112301); C, G. monticola Shy, Ng \& Yu, 1994, $18.3 \times 14.1 \mathrm{~mm}$ (NSYSU F92030104); 1, dorsal view of terminal segment, distal part magnified; 2, dorsal view of terminal segment; 3, synovial membrane. Scales: $100 \mu \mathrm{m}$. 
with T4 setae clustered on sections 3-4 and more densely distributed than on outer margin, the setae of which barely reach sections 3-4.

Female gonopores. - Diameter 1.5-1.9 × 1.0-1.1 mm, distance between pores approx. $1.1 \mathrm{~mm}$.

\section{Geothelphusa monticola Shy, Ng \& Yu, 1994}

(fig. 6C1-3)

Material examined with SEM. — Male $(18.3 \times 14.1 \mathrm{~mm})$ (NSYSU F92030104): TLG1 = 4.7 $\mathrm{mm} ; \mathrm{AD}=51.7 \mu \mathrm{m} ; \mathrm{LD}=180.6 \mu \mathrm{m} ; \mathrm{SR}=4-5 ; \mathrm{SS}=4 / 19 ; \mathrm{TD}=102^{\circ}$; Hoping, Songmao, Taichung county, coll. W.-J. Chen \& Z.-S. Sun, 1 Mar. 2003.

Other material. - One male $(20.64 \times 16.12 \mathrm{~mm})$ (NTOU F10112), Hoping, Sheauyeakow, Taichung county, coll. J.-Y. Shy \& W.-L. Tsay, 28 June 1993; 1 male 1 female (NSYSU F92030103), Hoping, Siyuan, Taichung county, coll. W.-J. Chen \& Z.-S. Sun, 1 Mar. 2003; 3 males, 1 female $(17.1 \times 14.3 \mathrm{~mm})(\mathrm{NSYSU}$ F93111301), Lishan, Taichung county, coll. W.-J. Chen \& C.-F. Tseng, 13 Nov. 2004.

Terminal segment. - Curved outwards and reaching slightly beyond sternal condyle in situ, distal part with 4-5 rings of scales (fig. 6C1) and a mean maximum diameter of $169.9 \mu \mathrm{m}$; dorsal aspect of terminal segment with 4 long T3 setae and 19 short T3 setae (fig. 6C2); diameter of apical opening of ejaculatory canal about $51.7 \mu \mathrm{m}$; length and width of base about $1.0 \mathrm{~mm}$ and $298.8 \mu \mathrm{m}$, respectively.

Sub-terminal segment. — Width about $2.1 \mathrm{~mm}$; with synovial membrane of which ratio length : width is about 2.8 , basal margin low, narrow, concave and top margin oblique (fig. 6C3); with one low protuberance on proximal outer angle. Proximal margin and base of sub-terminal segment with setae, inner margin with T4 setae clustered on sections 3-4 and more densely distributed than on outer margin, the setae of which barely reach sections 3-4.

Female gonopores. - Diameter $2.0 \times 0.9 \mathrm{~mm}$, distance between pores approx. $1.3 \mathrm{~mm}$.

Geothelphusa nanao Shy, Ng \& Yu, 1994 (fig. 7A1-3)

Material examined with SEM. - Male $(30.2 \times 23.3 \mathrm{~mm})($ NSYSU F0815042): TLG1 = 7.6 $\mathrm{mm} ; \mathrm{AD}=90.1 \mu \mathrm{m} ; \mathrm{LD}=270.1 \mu \mathrm{m} ; \mathrm{SR}=8-9, \mathrm{SS}=3 / 27 ; \mathrm{TD}=98^{\circ}$; Nanao, Chinyang, Ilan county, coll. W.-J. Chen \& J.-Y. Shy, 15 Aug. 2001.

Other material. - Two males, 5 females (largest female $25.9 \times 20.0 \mathrm{~mm}$ ) (NSYSU F90081504), Nanao, Chinyang, Ilan county, coll. W.-J. Chen \& J.-Y. Shy, 15 Aug. 2001.

Terminal segment. - Curved outwards and reaching below sternal condyle in situ, distal part with 8-9 rings of scales (fig. 7A1) and a maximum diameter of $270.1 \mu \mathrm{m}$; dorsal aspect of terminal segment with 3 long T3 setae and 27 short T3 setae (fig. 7A2); diameter of apical opening of ejaculatory canal about $90.1 \mu \mathrm{m}$; length and width of base about $0.9 \mathrm{~mm}$ and $506.1 \mu \mathrm{m}$, respectively. 


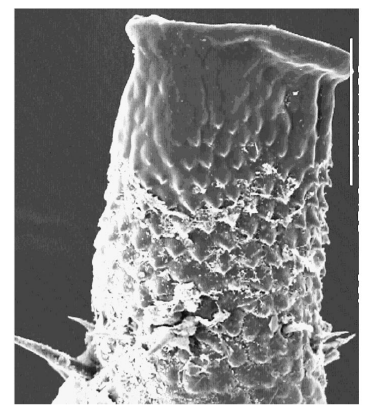

A1

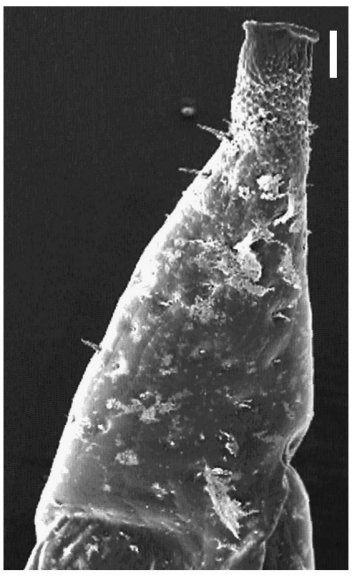

A2

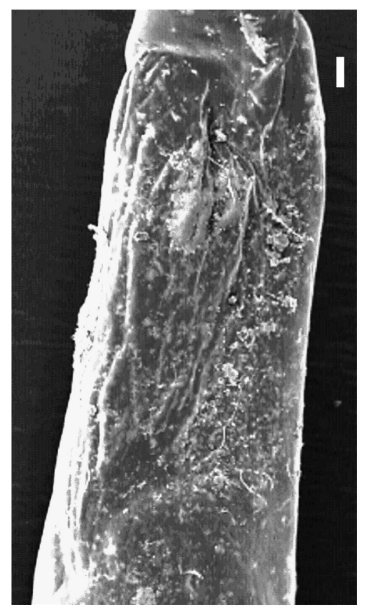

A3

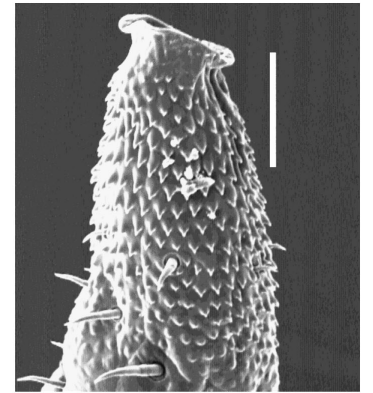

B1

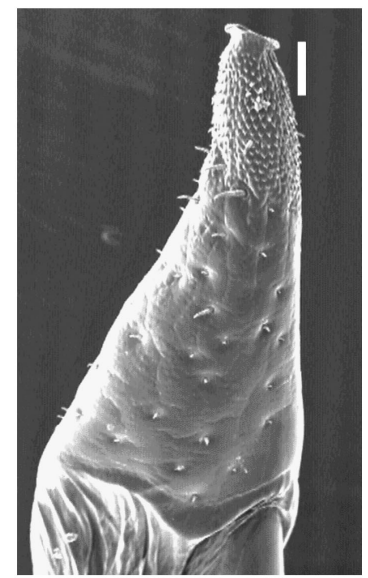

B2

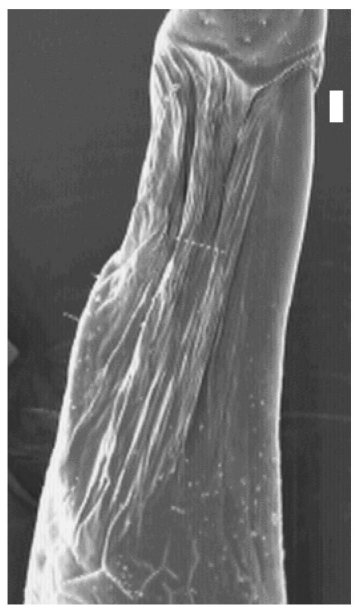

B3

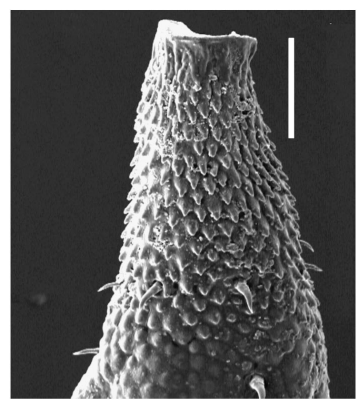

C1

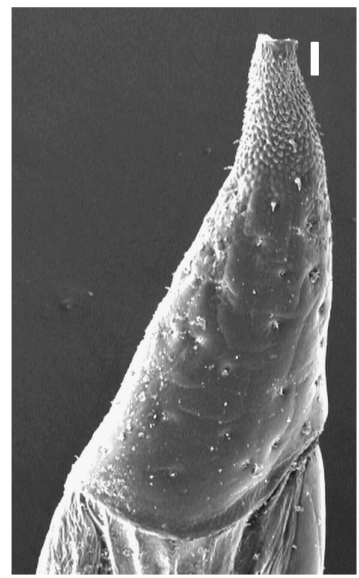

C2

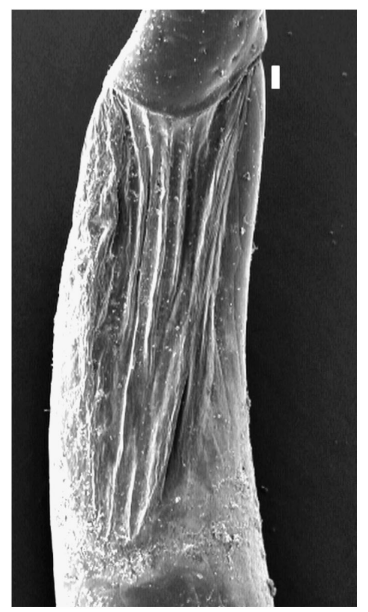

C3

Fig. 7. Micromorphology of the right G1 of freshwater crabs of the genus Geothelphusa Stimpson, 1858 by SEM. A, G. nanao Shy, Ng \& Yu, 1994, $30.2 \times 23.3 \mathrm{~mm}$ (NSYSU F0815042); B, G. nanhsi Shy, Ng \& Yu, 1994, $25.2 \times 20.3$ mm (NSYSU F89110401); C, G. olea Shy, Ng \& Yu, 1994, $30.6 \times 24.1 \mathrm{~mm}$ (NSYSU F90102202); 1, dorsal view of terminal segment, distal part magnified; 2 , dorsal view of terminal segment; 3 , synovial membrane. Scales: $100 \mu \mathrm{m}$. 
Sub-terminal segment. - Width about $2.7 \mathrm{~mm}$; with synovial membrane of which ratio length : width is about 3.5 , basal margin v-shape and top margin horizontal (fig. 7A3); with one protuberance on proximal outer angle. Proximal margin and base of sub-terminal segment with setae, inner margin with T4 setae clustered on sections 3-4 and more densely distributed than on outer margin, the setae of which barely reach sections 3-4.

Female gonopores. - Diameter $2.5 \times 1.5-1.6 \mathrm{~mm}$, distance between pores approx. 1.1-1.2 $\mathrm{mm}$.

\section{Geothelphusa nanhsi Shy, $\mathrm{Ng} \& \mathrm{Yu}, 1994$}

(fig. 7B1-3)

Material examined with SEM. - Male $(25.2 \times 20.3 \mathrm{~mm})($ NSYSU F89110401): TLG1 = 7.3 $\mathrm{mm} ; \mathrm{AD}=67.7 \mu \mathrm{m} ; \mathrm{LD}=181.6 \mu \mathrm{m} ; \mathrm{SR}=14-15 ; \mathrm{SS}=5 / 27 ; \mathrm{TD}=128^{\circ}$; Neimen, Kaohsiung county, coll. W.-J. Chen, 4 Nov. 2000; 1 male $(23.3 \times 18.3 \mathrm{~mm})$ (NTOU F10198), Nanhsi, Tainan county, coll. J.-Y. Shy \& W.-L. Tsay, 7 Aug. 1992.

Other material. - Two males, 1 female (female $29.8 \times 23.2 \mathrm{~mm}$ ) (NSYSU F93112104), Nanhsi, Tainan county, coll. W.-J. Chen, 21 Nov. 2004; 3 males (largest $26.2 \times 21.0 \mathrm{~mm}$ ) (NSYSU F91102605), Nanhsi, Tainan county, coll. W.-J. Chen, 26 Oct. 2002; 1 male, 1 female (female $29.8 \times 23.2 \mathrm{~mm})(\mathrm{NSYSU}$ F91051106), Nanhsi, Tainan county, coll. W.-J. Chen, 11 May 2002.

Terminal segment. - Curved outwards and reaching beyond sternal condyle in situ, distal part with 14-17 rings of scales (fig. 7B1) and a mean maximum diameter of $178.8 \mu \mathrm{m}$; dorsal aspect of terminal segment with 5 long T3 setae and 27 short T3 setae (fig. 7B2); diameter of apical opening of ejaculatory canal about $67.7 \mu \mathrm{m}$; length and width of base about $1.1 \mathrm{~mm}$ and $487.5 \mu \mathrm{m}$, respectively.

Sub-terminal segment. - Mean width about $2.3 \mathrm{~mm}$; with synovial membrane of which ratio length : width is about 4.4, basal margin low, concave and top margin slightly convex (fig. 7B3); with one faint protuberance on proximal outer angle. Proximal margin and base of sub-terminal segment with setae, inner margin with T4 setae clustered mainly on section 4 and more densely distributed than on outer margin, the setae of which barely reach section 4 .

Female gonopores. - Diameter 2.8-3.3 × 1.8-2.0 mm, distance between pores approx. $1.4-1.8 \mathrm{~mm}$.

Geothelphusa olea Shy, $\mathrm{Ng} \& \mathrm{Yu}, 1994$

(fig. 7C1-3)

Material examined with SEM. - Male $(30.6 \times 24.1 \mathrm{~mm})($ NSYSU F90102202): TLG1 = 7.2 $\mathrm{mm} ; \mathrm{AD}=68.7 \mu \mathrm{m} ; \mathrm{LD}=274.8 \mu \mathrm{m} ; \mathrm{SR}=10-11 ; \mathrm{SS}=3 / 29, \mathrm{TD}=126^{\circ} ;$ Paiho, Tainan county, coll. W.-J. Chen, 22 Oct. 2001.

Other material. - One male, 2 females (largest female $38.1 \times 30.1 \mathrm{~mm}$ ) (NSYSU F91102602), Paiho, Tainan county, coll. W.-J. Chen, 26 Oct. 2002; 1 male, 1 female (female $36.2 \times 28.2 \mathrm{~mm}$ ) (NSYSU F91102604), Tungshan, Tainan county, coll. W.-J. Chen, 26 Oct. 2002; 4 males (largest 
$27.4 \times 22.1 \mathrm{~mm})($ NSYSU F91100102), Nanhsi, Tainan county, coll. W.-J. Chen, 1 Oct. 2002; 2 males (largest $32.8 \times 25.9 \mathrm{~mm}$ ) (NSYSU F91122202), Yuching, Tainan county, coll. W.-J. Chen, 22 Dec. 2002.

Terminal segment. - Curved outwards and reaching below sternal condyle in situ, distal part with 10-11 rings of scales (fig. 7C1) and a mean maximum diameter of $261.5 \mu \mathrm{m}$; dorsal aspect of terminal segment with 3 long T3 setae and 29 short T3 setae (fig. 7C2); diameter of apical opening of ejaculatory canal about $68.7 \mu \mathrm{m}$; length and width of base about $1.4 \mathrm{~mm}$ and $570.4 \mu \mathrm{m}$, respectively.

Sub-terminal segment. — Width about $3.1 \mathrm{~mm}$; with synovial membrane of which ratio length : width is about 2.8 , basal margin low, concave and top margin convex (fig. 7C3); with one protuberance on proximal outer angle. Proximal margin and base of sub-terminal segment with setae, inner margin with T4 setae clustered mainly on section 4 and more densely distributed than on outer margin, the setae of which barely reach section 4 .

Female gonopores. - Diameter 3.0-3.4 × 2.0-2.4 mm, distance between pores approx. $1.8-2.0 \mathrm{~mm}$.

\section{Geothelphusa takuan Shy, $\mathrm{Ng} \& \mathrm{Yu}, 1994$}

$$
\text { (fig. 8A1-3) }
$$

Material examined with SEM. - Male $(17.4 \times 13.0 \mathrm{~mm})($ NSYSU F92070902): TLG1 = 4.6 $\mathrm{mm} ; \mathrm{AD}=43.8 \mu \mathrm{m} ; \mathrm{LD}=221.3 \mu \mathrm{m} ; \mathrm{SR}=6-7 ; \mathrm{SS}=13 / 20 ; \mathrm{TD}=60^{\circ}$; Fuhsing, Takuan, Taoyuan county, coll. W.-J. Chen \& C.-F. Tseng, 9 July 2003.

Other material. - Three males (largest $16.4 \times 12.5 \mathrm{~mm}$ ) (NSYSU F92070921), Fuhsing, Takuan, Taoyuna county, coll. W.-J. Chen \& C.-F. Tseng, 9 July 2003; 3 males 4 females (largest female $21.3 \times 16.1 \mathrm{~mm}$ ) (NSYSU F92022906), Tatung, Mingchi, Ilan county, coll. W.-J. Chen \& Z.-S. Sun, 29 Feb. 2003.

Terminal segment. - Curved inwards and reaching beyond sternal condyle in situ, distal part with 6-7 rings of scales (fig. 8A1) and a mean maximum diameter of $210.8 \mu \mathrm{m}$; dorsal aspect of terminal segment with 13 long T3 setae and 20 short T3 setae (fig. 8A2); diameter of apical opening of ejaculatory canal about $43.8 \mu \mathrm{m}$; length and width of base about $0.8 \mathrm{~mm}$ and $341.7 \mu \mathrm{m}$, respectively.

Sub-terminal segment. - Width about $1.9 \mathrm{~mm}$; with synovial membrane of which ratio length : width is about 2.9 , basal margin low, broad, concave and top margin horizontal (fig. 8A3); with one protuberance on proximal outer angle. Proximal margin and base of sub-terminal segment with setae, inner margin with T4 setae clustered on section 4 and more densely distributed than on outer margin, the setae of which barely reach sections 3-4.

Female gonopores. - Diameter 2.0-2.1 $\times$ 0.9-1.0 mm, distance between pores approx. $1.2 \mathrm{~mm}$. 


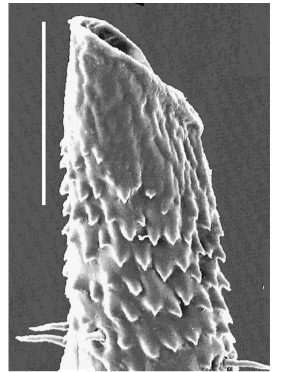

A1

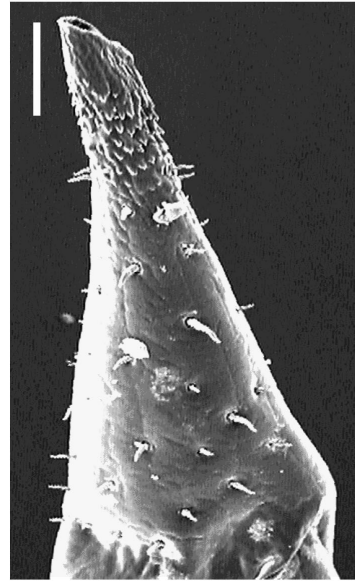

A2

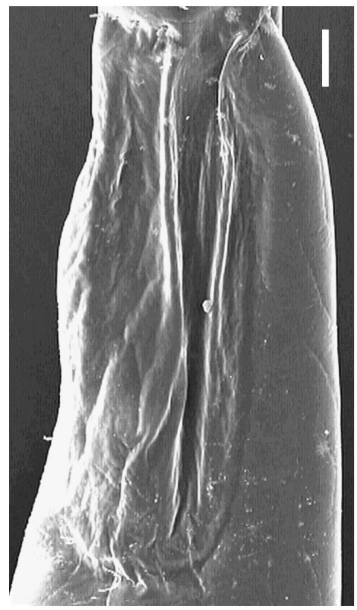

A3

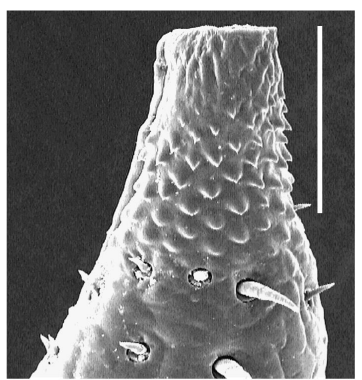

B1

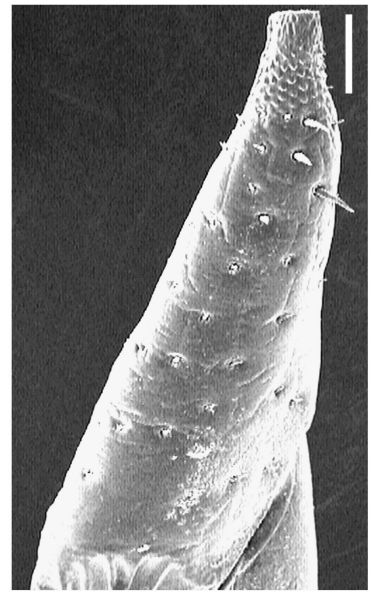

B2

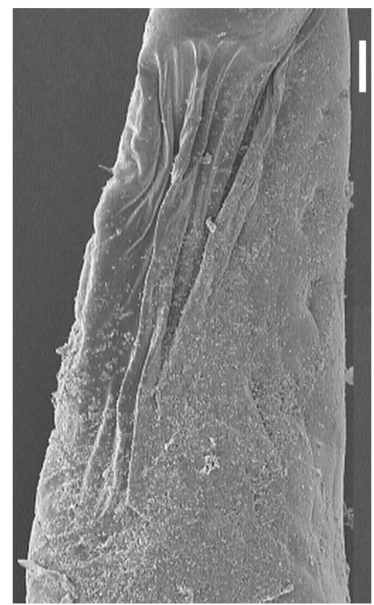

B3

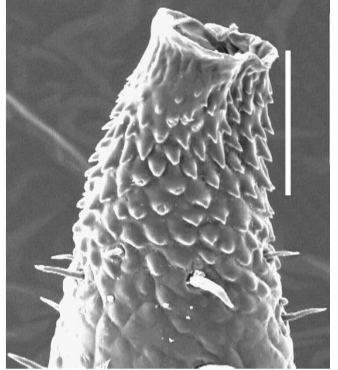

\section{C1}

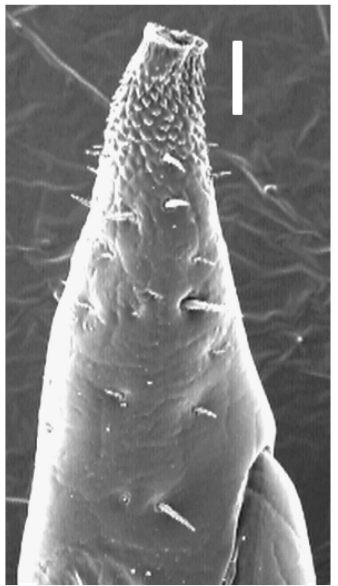

C2

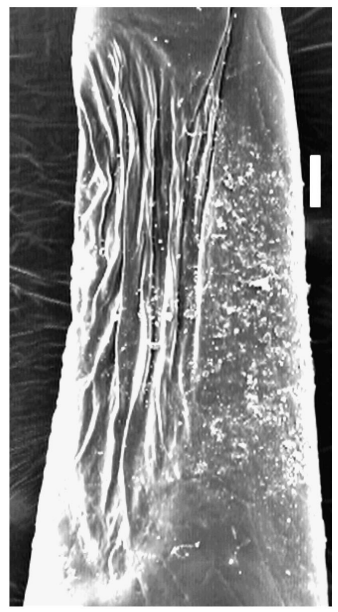

C3

Fig. 8. Micromorphology of the right G1 of freshwater crabs of the genus Geothelphusa Stimpson, 1858 by SEM. A, G. takuan Shy, Ng \& Yu, 1994, $17.4 \times 13.0$ mm (NSYSU F92070902); B, G. tali Shy, Ng \& Yu, 1994, $18.6 \times 14.3$ mm (NSYSU F7100301); C, G. taroko Shy, Ng \& Yu, 1994, $20.6 \times 15.6$ mm (NSYSU F89081206); 1, dorsal view of terminal segment, distal part magnified; 2, dorsal view of terminal segment; 3 , synovial membrane. Scales: $100 \mu \mathrm{m}$. 
Geothelphusa tali Shy, $\mathrm{Ng} \& \mathrm{Yu}, 1994$

(fig. 8B1-3)

Material examined with SEM. - Male $(18.6 \times 14.3 \mathrm{~mm})(\mathrm{NSYSU}$ F7100301): TLG1 = 4.4 $\mathrm{mm} ; \mathrm{AD}=41.1 \mu \mathrm{m} ; \mathrm{LD}=146.5 \mu \mathrm{m} ; \mathrm{SR}=5-6 ; \mathrm{SS}=3 / 30 ; \mathrm{TD}=80^{\circ}$; Tali, Ilan county, coll. W.-J. Chen \& C.-F. Tseng, 10 July 2003.

Other material. - One male, 3 females (largest female $23.1 \times 18.0 \mathrm{~mm}$ ) (NSYSU F7100302), Tali, Ilan county, coll. W.-J. Chen \& C.-F. Tseng, 10 July 2003.

Terminal segment. - Curved outwards and reaching below sternal condyle in situ, distal part with 5-6 rings of scales (fig. 8B1) and a mean maximum diameter of $145.4 \mu \mathrm{m}$; dorsal aspect of terminal segment with 3 long T3 setae and 30 short T3 setae (fig. 8B2); diameter of apical opening of ejaculatory canal about $41 \mu \mathrm{m}$; length and width of base about $0.9 \mathrm{~mm}$ and $275.7 \mu \mathrm{m}$, respectively.

Sub-terminal segment. - Mean width about $1.4 \mathrm{~mm}$; with synovial membrane of which ratio length : width is about 3.9, basal margin oblong and top margin curved (fig. 8B3); with one protuberance on proximal outer angle. Proximal margin and base of sub-terminal segment with setae, inner margin with T4 setae clustered on sections 3-4 and more densely distributed than on outer margin, of which setae barely reach section 4 .

Female gonopores. - Diameter 1.7-2.7 × 1-1.8 mm, distance between pores approx. 1.0-1.7 $\mathrm{mm}$.

Geothelphusa taroko Shy, Ng \& Yu, 1994

(fig. 8C1-3)

Material examined with SEM. - Male $(20.6 \times 15.6 \mathrm{~mm})($ NSYSU F89081206): TLG1 = 4.9 $\mathrm{mm} ; \mathrm{AD}=70.4 \mu \mathrm{m} ; \mathrm{LD}=195.0 \mu \mathrm{m} ; \mathrm{SR}=6-8 ; \mathrm{SS}=6 / 17$; $\mathrm{TD}=112^{\circ}$; Hsiulin, Hwalien county, coll. W.-J. Chen \& J.-Y. Shy, 12 Aug. 2000; 1 male $(23.2 \times 17.7$ mm) (NSYSU F91070303): $\mathrm{TLG} 1=5.7 \mathrm{~mm} ; \mathrm{AD}=66.0 \mu \mathrm{m} ; \mathrm{LD}=228.1 \mu \mathrm{m} ; \mathrm{SR}=7-7 ; \mathrm{SS}=8 / 13 ; \mathrm{TD}=109^{\circ} ;$ Hsiulin, Lushui, Hwalien county, coll. W.-J. Chen \& Z.-S. Sun, 3 July 2002.

Other material. - Two females (largest 26.0 × 19.3 mm) (NSYSU F89081206), Hsiulin, Hwalien county, coll. W.-J. Chen \& J.-Y. Shy, 12 Aug. 2000; 2 males, 4 females (largest female $26.7 \times 20.9$ mm) (NSYSU F91070302), Hsiulin, Lushui, Hwalien county, coll. W.-J. Chen \& Z.-S. Sun, 3 July 2002 .

Terminal segment. - Curved outwards and reaching slightly below sternal condyle in situ, distal part with 6-8 rings of scales (fig. $8 \mathrm{C} 1$ ) and a mean maximum diameter of $194.7 \mu \mathrm{m}$; dorsal aspect of terminal segment with 6-8 long T3 setae and 13-19 short T3 setae (fig. 8C2); mean diameter of apical opening of ejaculatory canal about $66.4 \mu \mathrm{m}$; length and width of base about $0.75 \mathrm{~mm}$ and $254.5 \mu \mathrm{m}$, respectively.

Sub-terminal segment. - Mean width about $1.83 \mathrm{~mm}$; with synovial membrane of which ratio length : width is about 4.2-4.3, basal margin v-shape and top margin convex (fig. 8C3); with one protuberance on proximal outer angle. Proximal 
margin and base of sub-terminal segment with setae, inner margin with T4 setae clustered on section 4 and more densely distributed than on outer margin, the setae of which barely reach section 4 .

Female gonopores. - Diameter 2.1-2.9 × 1.6-1.7 mm, distance between pores approx. $1.7 \mathrm{~mm}$.

\title{
Geothelphusa tawu Shy, Ng \& Yu, 1994
}

\author{
(fig. 9A1-3)
}

Material examined with SEM. - Male $(19.9 \times 15.8 \mathrm{~mm})($ NSYSU F89081137): TLG1 = 5.3 $\mathrm{mm} ; \mathrm{AD}=52.1 \mu \mathrm{m} ; \mathrm{LD}=175 \mu \mathrm{m} ; \mathrm{SR}=5-6, \mathrm{SS}=5 / 23, \mathrm{TD}=131^{\circ} ;$ Tajen, Taitung county, coll. W.-J. Chen \& J.-Y. Shy, 11 Aug. 2000; 1 male $(19.2 \times 15.0$ mm) (NSYSU F89081175), Tajen, Taitung county, coll. W.-J. Chen \& J.-Y. Shy, 11 Aug. 2000.

Other material. - One male, 2 females (largest female $18.3 \times 14.8 \mathrm{~mm}$ ) (NSYSU F92022701), Tajen, Taitung county, coll. W.-J. Chen \& C.-F. Tseng, 27 Feb. 2003; 3 males (largest $16.7 \times 13.6$ mm) (NSYSU F891114), Tajen, Taitung county, coll. W.-J. Chen \& C.-F. Tseng, 14 Nov. 2000.

Terminal segment. - Curved outwards and reaching slightly below sternal condyle in situ, distal part with 5-6 rings of scales (fig. 9A1) and a mean maximum diameter of $175 \mu \mathrm{m}$; dorsal aspect of terminal segment with 5 long T3 setae and 23 short T3 setae (fig. 9A2); diameter of apical opening of ejaculatory canal about $52.1 \mu \mathrm{m}$; length and width of base about $1.0 \mathrm{~mm}$ and $406.0 \mu \mathrm{m}$, respectively.

Sub-terminal segment. — Width about $1.6 \mathrm{~mm}$; with synovial membrane of which ratio length : width is about 2.7 , basal margin broad, v-shape and top margin slightly oblique (fig. 9A3); with one protuberance on proximal outer angle. Proximal margin and base of sub-terminal segment with setae, inner margin with T4 setae clustered on sections 3-4 and more densely distributed than on outer margin, the setae of which barely reach sections 3-4.

Female gonopores. - Diameter 1.6-1.9 $\times$ 0.9-1.0 mm, distance between pores approx. 1.1-1.4 $\mathrm{mm}$.

Geothelphusa tsayae Shy, $\mathrm{Ng} \& \mathrm{Yu}, 1994$ (fig. 9B1-3)

Material examined with SEM. - Male $(21.7 \times 17 \mathrm{~mm})($ NSYSU F890923A2): TLG1 = 5.4 $\mathrm{mm} ; \mathrm{AD}=48.4 \mu \mathrm{m} ; \mathrm{LD}=159.4 \mu \mathrm{m} ; \mathrm{SR}=10-11 ; \mathrm{SS}=3 / 19 ; \mathrm{TD}=124^{\circ} ;$ Meinung, Kaohsiung county, coll. W.-J. Chen, 23 Sept. 2000; 1 male $(27.8 \times 21.9$ mm) (NSYSU F91051905), Liukuei, Kaohsiung county, coll. W.-J. Chen, 19 May 2002.

Other material. - One male $(24.6 \times 18.9 \mathrm{~mm}), 1$ female $(29.6 \times 23.2 \mathrm{~mm})$ (NSYSU F93092502), Sanmin, Kaohsiung county, coll. W.-J. Chen, 25 Sept. 2004; 1 male $(21.5 \times 18.6 \mathrm{~mm})$ (NSYSU F890923A1), Meinung, Kaohsiung county, coll. W.-J. Chen, 23 Sept. 2000; 5 males (largest $27.9 \times 21.7 \mathrm{~mm})($ NSYSU F91052508), Liukuei, Kaohsiung county, coll. W.-J. Chen, 25 May 2002.

Terminal segment. - Curved outwards and reaching slightly below sternal condyle in situ, distal part with 10-11 rings of scales (fig. 9B1) and a mean 


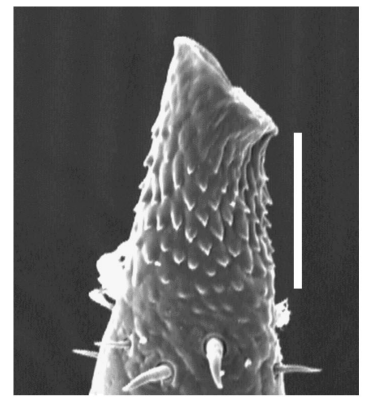

A1

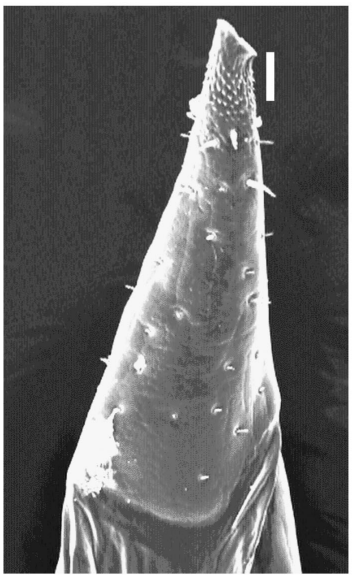

A2

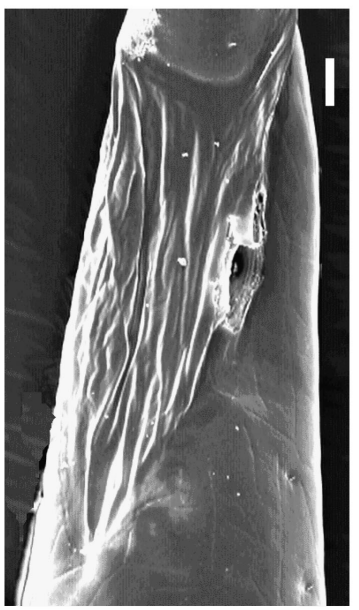

A3

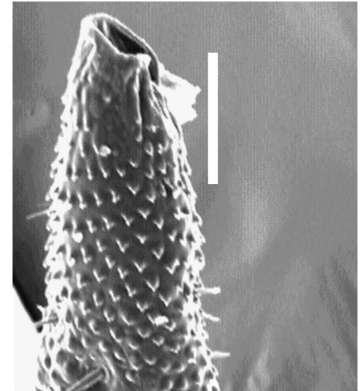

B1

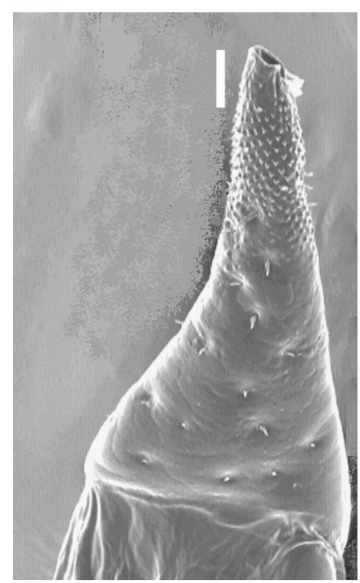

B2

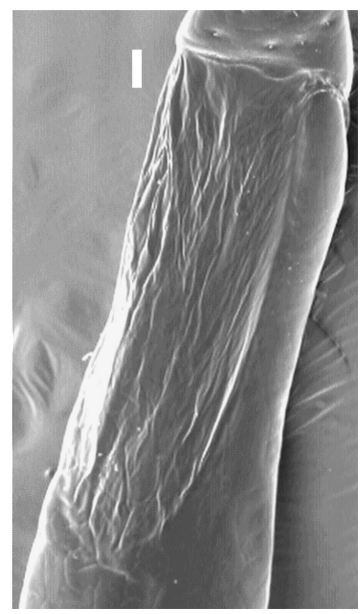

B3

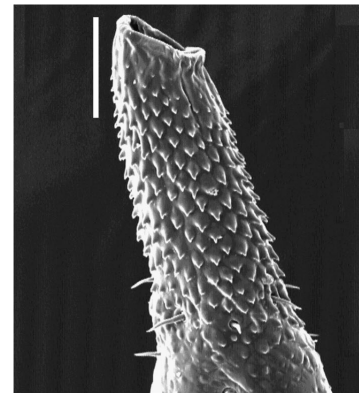

C1

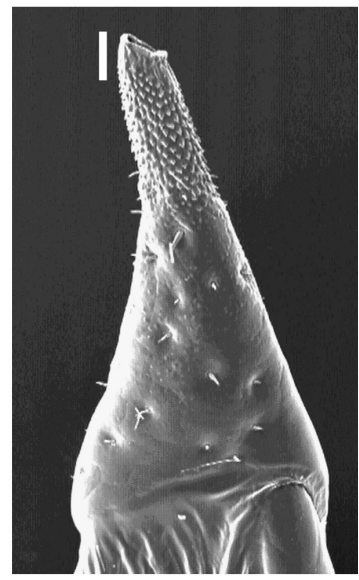

C2

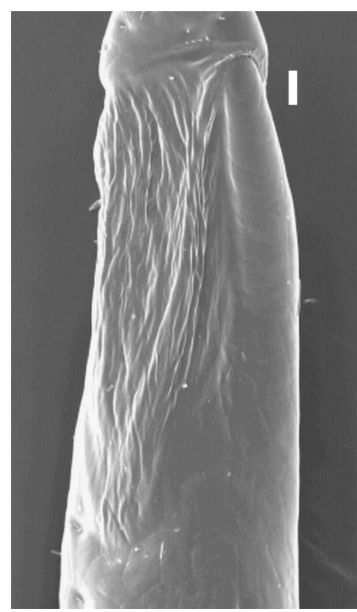

C3

Fig. 9. Micromorphology of the right G1 of freshwater crabs of the genus Geothelphusa Stimpson, 1858 by SEM. A, G. tawu Shy, Ng \& Yu, 1994, $19.9 \times 15.8$ mm (NSYSU F89081137); B, G. tsayae Shy, Ng \& Yu, 1994, $21.7 \times 17.0$ mm (NSYSU F890923A2); C, G. wutai Shy, Ng \& Yu, 1994, $23.3 \times 18.8 \mathrm{~mm}$ (NTOU 10081); 1, dorsal view of terminal segment, distal part magnified; 2, dorsal view of terminal segment; 3 , synovial membrane. Scales: $100 \mu \mathrm{m}$. 
maximum diameter of $148.9 \mu \mathrm{m}$; dorsal aspect of terminal segment with 3 long T3 setae and 19 short T3 setae (fig. 9B2); diameter of apical opening of ejaculatory canal about $48.4 \mu \mathrm{m}$; length and width of base about $0.8 \mathrm{~mm}$ and $451.2 \mu \mathrm{m}$, respectively.

Sub-terminal segment. - Mean width about $1.8 \mathrm{~mm}$; with synovial membrane of which ratio length : width about 3.7 , basal margin broad, concave and top margin horizontal (fig. 9B3); with one faint protuberance on proximal outer angle. Proximal margin and base of sub-terminal segment with setae, inner margin with T4 setae clustered mainly on section 4 and more densely distributed than on outer margin, the setae of which barely reach sections 3-4.

Female gonopores. - Diameter 2.6-2.7 × $1.5 \mathrm{~mm}$, distance between pores approx. $1.5 \mathrm{~mm}$.

Geothelphusa wutai Shy, Ng \& Yu, 1994

(fig. 9C1-3)

Material examined with SEM. - Male $(23.3 \times 18.8 \mathrm{~mm})($ NTOU 10081): TLG1 = $7.5 \mathrm{~mm}$; $\mathrm{AD}=55.3 \mu \mathrm{m} ; \mathrm{LD}=188.5 \mu \mathrm{m} ; \mathrm{SR}=11-11 ; \mathrm{SS}=2 / 22 ; \mathrm{TD}=137^{\circ} ;$ Wutai, Ila, Pingtung county, coll. H.-P. Yu, 12 July 1982.

Other material. - Five males (largest $19.0 \times 15.3 \mathrm{~mm}$ ), 10 females (largest $20.2 \times 16.0 \mathrm{~mm}$ ) (NTOU F10081), Wutai, Ila, Pingtung county, coll. H.-P. Yu, 12 July 1982.

Terminal segment. - Curved outwards and reaching beyond sternal condyle in situ, distal part with 11 rings of scales (fig. 9C1) and a maximum diameter of 188.5 $\mu \mathrm{m}$; dorsal aspect of terminal segment with 2 long T3 setae and 22 short T3 setae (fig. 9C2); diameter of apical opening of ejaculatory canal about $55.3 \mu \mathrm{m}$; length and width of base about $0.9 \mathrm{~mm}$ and $484.3 \mu \mathrm{m}$, respectively.

Sub-terminal segment. - Mean width about $1.8 \mathrm{~mm}$; with synovial membrane of which ratio length : width is about 4.0, basal margin low, broad, concave and top margin horizontal (fig. 9C3); with one faint protuberance on proximal outer angle. Proximal margin and base of sub-terminal segment with setae, inner margin with T4 setae clustered on sections 3-4 and more densely distributed than on outer margin, the setae of which barely reach section 4 .

Female gonopores. - Diameter $1.9 \times 1.0 \mathrm{~mm}$, distance between pores approx. $1.5 \mathrm{~mm}$.

\section{DISCUSSION}

The analysis of micromorphological structures of taxonomically important characters can help discriminate between species and may also contribute to our understanding of evolutionary pathways (Nielsen, 1998). In the present study, we selected 22 species of common freshwater crabs from Taiwan belonging to the 
genus Geothelphusa for examining the G1 with SEM. The detailed morphology of the G1 of these species is described above. For a more convenient comparison of the differences in the G1 between species, the main characteristics and ratios of measurements are provided also in table I. According to Shy (1994), adult male Geothelphusa had been divided into three body-size groups according to carapace width. We found as major differences between these three body-size groups the scattered setae (SS) as well as the rings of scales (SR) on the terminal segment of G1. Crabs of group L have specifically higher numbers than those of group $\mathrm{S}$. The length of the terminal segment of G1 is less in group M, and the shortest length occurs in individuals of G. dolichopodes, G. nanao, and G. wutai (table I).

The direction of the curve of the tip of G1 (TD) in ventral view, relative to the terminal segment, mostly has an angle greater than $95^{\circ}$, defined as curved outwards, except in G. takuan, G. eurysoma, and G. tali, where the tip is curved inwards. In Shy et al. (1994), the tips of G. olea, G. nanhsi, G. wutai, G. tsayae, $G$. bicolor, and G. lanyu were described as slightly curved inwards, too. We suggest these differences result from the way of taking the measurements, where we examined the tip at the apical opening of the ejaculatory canal, whereas the curve direction of the terminal segment was used by Shy et al. (1994).

The synovial membrane on G1 could be a key characteristic to discriminate between species. In 1995, a new genus, Ryukyum Ng \& Shokita, 1995 (Potamidae) was established for the terrestrial potamid crab from the Ryukyu Islands, and as one of the important characteristics the authors used in the structure of G1, which had a synovial membrane ( $\mathrm{Ng} \&$ Shokita, 1995). The presence of a well developed synovial membrane was mentioned as the main difference between the genera Ryukyum and Nanhaipotamon, as the latter lacked it (Ng \& Shokita, 1995). In the present study, the genus Geothelphusa is also shown to has a well developed synovial membrane on G1, and its micromorphology varies among species. For instance, G. tawu, G. lanyu, and G. lutao could easily be distinguished by the top margin of their synovial membrane. Furthermore, by comparison of the G1 under SEM, there are other differences among these three species, i.e., scattered setae, rings of scales, and the TLG1/SW ratio (table I). This despite the fact that Shih et al. (2004) used molecular methods to assess the systematics of a part of the southern Taiwanese Geothelphusa species, and suggested G. lanyu, G. lutao, and G. tawu could be conspecific. We assume that the variations in the micromorphology of the reproductive organs may have resulted in reproductive isolation as at step 2 of the allopatric model (Grant \& Grant, 1996). Reinforcement of the speciation process may also have been accomplished through various ecological pressures, or from a degree of reproductive incompatibility rather recently (Liou \& Price, 1994; Grant \& Grant, 1996; Schluter, 1996; Rundle \& Schluter, 1998; Servedio, 2000). The above results could hence support the taxonomic system of Shy et al. (1994) and that of $\mathrm{Ng}$ et al. (2001), too. 


\section{ACKNOWLEDGEMENTS}

We are greatly indebted to Prof. J.-Y. Shy of the National Penghu Institute of Technology for commenting on this manuscript, for providing information, and for checking the status of the types of some species; to three anonymous referees for valuable comments on a previous version of this manuscript; to Dr. H.-Y. Liu of the Department of Biological Sciences, National Sun Yat-sen University for help with SEM techniques; and to Mr. Z.-S. Sun and Miss C.-F. Tseng for help with field collections. This work was partially supported by a grant from the NSYSU and Ministry of Education from 2001-2003, Republic of China.

\section{REFERENCES}

ABELE, L. G., 1971. Scanning electron photomicrographs of brachyuran gonopods. Crustaceana, 21: $217-219$.

Chen, W. J., J. H. Cheng \& J. Y. SHY, 2005. On two new species of freshwater crabs (Crustacea: Decapoda: Brachyura: Potamidae) from southern Taiwan. Raffles Bull. Zool., 53 (1): 103-110.

— - 1998. A new species of feshwater crab, Geothelphusa neipu (Decapoda: Brachyura: Potamidae) from southern Taiwan. Abstr. Mtg. Taiwan Fish. Soc., Taipei, 1998: 154.

Chen, W. J., S. H. Tsai, M. J. Hsu \& J. H. Cheng, 2003. Freshwater crab fauna in southern Taiwan: 1-123. (Kaohsiung County Government, Kaohsiung). [In Chinese.]

DAI, A. Y., 1999. Fauna Sinica. Crustacea: Decapoda: Parathelphusidae, Potamidae: 1-501, pls. 1-30. (Science Press, Beijing).

Felgenhauer, B. E., 1987. Techniques for preparing crustaceans for scanning electron microscopy. Journ. Crust. Biol., 7: 71-76.

Grant, P. G. \& B. R. Grant, 1996. Speciation and hybridization in island birds. Phil. Trans. Roy. Soc. London, (B) 351: 765-772.

INGLE, R., 1992. Larval stages of northeastern Atlantic crabs: 1-363. (Chapman and Hall, London).

LIOU, L. W. \& T. D. PRICE, 1994. Speciation by reinforcement of premating isolation. Evolution, 48 (5): 1451-1459.

MAYR, E. \& P. D. Ashlock, 1991. Principles of systematic zoology: 1-473. (McGraw-Hill, New York).

NiELSEN, C., 1998. Morphological approaches to phylogeny. American Zool., 38: 942-952.

NG, P. K. L., 1988. The freshwater crabs of Peninsular Malaysia and Singapore: 1-156, figs. 1-63, pls. 1-4. (University of Singapore Press, Singapore).

NG, P. K. L. \& P. NAiYAnetr, 1993. New and recently described freshwater crabs (Crustacea: Decapoda: Brachyura: Potamidae, Gecarcinucidae and Parathelphusidae) from Thailand. Zoologische Verhandelingen, Leiden, 284: 1-117.

NG, P. K. L. \& S. ShokitA., 1995. Ryukyum, a new genus of terrestrial crab from the Ryukyu islands (Brachyura: Potamidae). Crustacean Research, 24: 1-7.

NG, P. K. L., C. H. WANG, P. H. Ho \& H. T. SHIH, 2001. An annotated checklist of brachyuran crabs from Taiwan (Crustacea: Decapoda). Natn. Taiwan Mus. spec. Publ. Ser., 11: 1-86.

RundLE, H. D. \& D. SCHLUTER, 1998. Reinforcement of stickleback mate preferences: sympatry breeds contempt. Evolution, 52 (1): 200-208.

SChlUTER, D., 1996. Ecological causes of adaptive radiation. The American Naturalist, 148 (suppl.): S40-S64.

SERVEDIO, M. R., 2000. Reinforcement and the genetics of nonrandom mating. Evolution, 54 (1): 21-29. 
Shin, H. T., P. K. L. NG \& H. W. Chang, 2004. Systematics of the genus Geothelphusa (Crustacea: Decapoda: Brachyura: Potamidae) from southern Taiwan: a molecular appraisal. Zoological Studies, Taipei, 43 (3): 561-570.

SHY, J. Y., 1994. Studies on the taxonomy, distribution and larval development of fresh-water shrimps and crabs in Taiwan: 1-181. (Ph.D. Dissertation, Taiwan Ocean University, Keelung). [In Chinese.]

— - 2005. A new species of freshwater crab of the genus Geothelphusa Stimpson, 1858 (Crustacea: Decapoda: Brachyura: Potamidae) from Taiwan. Raffles Bull. Zool., 53 (1): 99102.

SHY, J. Y. \& H. P. YU, 1999. The freshwater crabs of Taiwan: 1-116. (National Museum of Marine Biology and Aquarium, Pingtung). [In Chinese.]

ShY, J. Y., P. K. L. NG \& H. P. YU, 1994. Crabs of the genus Geothelphusa Stimpson, 1858 (Crustacea: Decapoda: Brachyura: Potamidae) from Taiwan, with descriptions of 25 new species. Raffles Bull. Zool., 42 (4): 781-846.

Shy, J. Y., W. J. CHEN \& J. H. CHENG, 2000. Redescription of the freshwater crab Geothelphusa neipu Chen, Cheng \& Shy, 1998 (Crustacea: Decapoda: Brachyura: Potamidae) from southern Taiwan. Raffles Bull. Zool., 48 (1): 147-151.

TAN, S. H. \& H. C. LIU, 1998. Two new species of Geothelphusa (Decapoda: Brachyura: Potamidae) from Taiwan. Zoological Studies, Taipei, 37 (4): 286-290. 